\title{
Article \\ Complete Genome Sequence, Molecular Characterization and Phylogenetic Relationships of a Novel Tern Atadenovirus
}

\author{
Alina Matsvay ${ }^{1,2, *}$, Marina Dyachkova ${ }^{1}$, Ivan Mikhaylov ${ }^{1}$, Daniil Kiselev ${ }^{3}{ }^{\circledR}$, Anna Say ${ }^{1} \oplus$, Valentina Burskaia ${ }^{4}$,

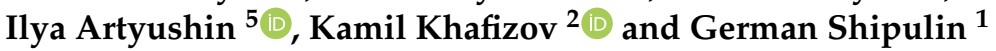

1 Federal State Budgetary Institution “Centre for Strategic Planning and Management of Biomedical Health Risks" of the Federal Medical Biological Agency, 119121 Moscow, Russia; MDyachkova@cspmz.ru (M.D.); IMkhaylov@cspmz.ru (I.M.); ASay@cspmz.ru (A.S.); shipgerman@gmail.com (G.S.)

2 Moscow Institute of Physics and Technology, National Research University, 115184 Moscow, Russia; kkhafizov@gmail.com

3 Institute for Neurosciences of Montpellier, University of Montpellier, INSERM, 34091 Montpellier, France; daniil.kiselev@inserm.fr

4 Skolkovo Institute of Science and Technology, 143026 Moscow, Russia; valya.burskaya@gmail.com

5 Faculty of Biology, Lomonosov Moscow State University, 119991 Moscow, Russia; sometyx@gmail.com

* Correspondence: matsvai@phystech.edu

\section{check for}

updates

Citation: Matsvay, A.; Dyachkova, M.; Mikhaylov, I.; Kiselev, D.; Say, A.; Burskaia, V.; Artyushin, I.; Khafizov, K.; Shipulin, G. Complete Genome Sequence, Molecular Characterization and Phylogenetic Relationships of a Novel Tern Atadenovirus. Microorganisms 2022, 10, 31. https://doi.org/10.3390/ microorganisms10010031

Academic Editor: Stefan Vilcek

Received: 5 December 2021

Accepted: 22 December 2021

Published: 24 December 2021

Publisher's Note: MDPI stays neutral with regard to jurisdictional claims in published maps and institutional affiliations.

Copyright: (C) 2021 by the authors. Licensee MDPI, Basel, Switzerland. This article is an open access article distributed under the terms and conditions of the Creative Commons Attribution (CC BY) license (https:// creativecommons.org/licenses/by/ $4.0 /)$.

\begin{abstract}
Discovery and study of viruses carried by migratory birds are tasks of high importance due to the host's ability to spread infectious diseases over significant distances. With this paper, we present and characterize the first complete genome sequence of atadenovirus from a tern bird (common tern, Sterna hirundo) preliminarily named tern atadenovirus 1 (TeAdV-1). TeAdV-1 genome is a linear double-stranded DNA molecule, 31,334 base pairs which contain 30 methionine-initiated open reading frames with gene structure typical for Atadenovirus genus, and the shortest known inverted terminal repeats (ITRs) within the Atadenovirus genus consisted of 25 bases. The nucleotide composition of the genome is characterized by a low $\mathrm{G}+\mathrm{C}$ content $(33.86 \%)$, which is the most AT-rich genome of known avian adenoviruses within Atadenovirus genus. The nucleotide sequence of the TeAdV-1 genome shows high divergence compared to known representatives of the Atadenovirus genus with the highest similarity to the duck atadenovirus 1 (53.7\%). Phylogenetic analysis of the protein sequences of core genes confirms the taxonomic affiliation of the new representative to the genus Atadenovirus with the degree of divergence from the known representatives exceeding the interspecies distance within the genus. Thereby we proposed a novel TeAdV-1 to be considered as a separate species.
\end{abstract}

Keywords: Adenoviridae; Atadenovirus; tern atadenovirus 1; genome annotation; phylogenetics

\section{Introduction}

Adenoviruses (AdVs) are common pathogens capable of replicating in almost all classes of vertebrates [1]. The family is divided into 6 genera: Atadenovirus, Aviadenovirus, Ichtadenovirus, Mastadenovirus, Siadenovirus, and recently accepted Testadenovirus [2].

Family members are medium-sized, non-enveloped viruses whose genetic information is contained in a double-stranded DNA molecule of variable size from 26 to $48 \mathrm{~kb}$, the ends of which harbor inverted terminal repeats (ITR) found in all AdVs [3]. The genomes of all AdVs have a similar structure. The central part of the genome consists of a conservative set of genes encoding household proteins that are necessary for the implementation of the life cycle of the virus. They are required for viral DNA replication (DNA polymeraseDNApol, terminal protein precursor-pTP, DNA-binding protein-DBP), involved in DNA encapsidation ( $52 \mathrm{~K}$ and IVa2 proteins), and building virion architecture (penton base, hexon, fiber, pIIIa, pVI, pVII, pVIII, pX, protease, $100 \mathrm{~K}$ protein, and $33 \mathrm{~K}$ protein) [4]. Atadenovirus representatives additionally have genus-specific genes for $\mathrm{p} 32 \mathrm{~K}$ and LH3 
(E1B homolog) proteins [5]. At the end of the DNA molecule, there is a variable region, whose sequence is usually unique for each species.

Birds are common hosts for AdVs of various genera, including Aviadenovirus, Atadenovirus, and Siadenovirus, many of which are pathogenic and often cause deadly diseases [1]. Infections carried by migratory birds can potentially spread over significant distances. It has been suggested that under some conditions, AdVs could be more virulent in non-hostadapted species than in their typical host [6]. A recent global systematic review carried out by Borkenhagen and colleagues [7] demonstrated substantial evidence suggesting AdVs have previously crossed host species barriers and this is likely to be repeated in the future. In some cases, the cross-species transmission of viruses may have large-scale consequences, such as, for example, global pandemics of fatal infectious diseases. A striking example is the relatively recent panzootic bird flu caused by the highly pathogenic avian influenza virus of type H5N1 [8]. In the human population, outbreaks of zoonotic viral infections have often escalated into extremely dangerous epidemics on a global scale, for example, the 2009 swine flu pandemic caused by the swine influenza virus of type H1N1 [9,10], as well as the ongoing COVID-19 pandemic caused by the SARS-CoV-2 coronavirus [11,12], and multiple others. Such pandemics are not only highly lethal but have serious socioeconomic consequences. Therefore the discovery and study of infectious agents of potential superspreaders [13] are tasks of high importance.

During the present study, we sequenced, assembled, and characterized the first complete genome of a new, previously undescribed tern adenovirus - tern atadenovirus 1 (TAdV-1) isolated from a bird, common tern (Sterna hirundo) as well as determined its taxonomic position and phylogenetic relationships with other currently known AdVs. We also studied the molecular evolution of the core genes of AdVs in the genome of the TeAdV-1 and the genomes of Atadenovirus in general. Analysis of positive selection helped us to elucidate the evolutionary processes occurring on the background of divergence, speciation, and adaptation of the virus to the host. To date, tern adenoviruses have not yet been described in publications.

\section{Materials and Methods}

\subsection{Sampling}

The sample used in this study belongs to the Common tern (Sterna hirundo) and was part of the collection of biological samples obtained from migratory birds in the near-water complex [14]. Bird droppings were collected on the banks of the Yenisei River near the village of Mirnoye (Russia, Siberia, Krasnoyarsk Region). The collection of samples was carried out without direct contact with animals, no invasive interventions with animals were performed.

Samples of biological materials were placed into sterile tubes with a transport medium (Reagent for transportation and storage of clinical material, Amplisens, Moscow, Russia) and transported to the laboratory within $48 \mathrm{~h}$ where they were stored in a low-temperature refrigerator (minus $82{ }^{\circ} \mathrm{C}$ ) until required for the experiment.

\subsection{Sample Preparation and Sequencing}

Nucleic acids were isolated with Allprep DNA/RNA mini kit (Qiagen, Hilden, Germany) following the manufacturer's instructions and used for all subsequent procedures.

Preliminary screening for common viral pathogens was carried out by multiplex PCR with a pool of 26 primer pairs and subsequent sequencing of obtained amplicons on the Ion S5 System (Thermo Fisher Scientific, Waltham, MA, USA) as described earlier [14].

Extracted DNA was used for library preparation with NEBNext Ultra II DNA Library Prep Kit (New England Biolabs, Ipswich, MA, USA) in accordance with the manufacturer's protocol after preliminary ultrasonic fragmentation using M220 Focused-ultrasonicator (Covaris, Woburn, MA, USA). Sequencing was performed on the Illumina MiSeq platform (Illumina, San Diego, CA, USA) with MiSeq Reagent Kit v2 (500-cycles) (Illumina, USA). A total of 1,462,033 paired-end reads were obtained for this sample. 


\subsection{Assembly and Genome Annotation}

The de novo assembly was performed using the SPAdes software v.3.15.3 [15] with the "careful" option activated. A total of 24,465 contigs were obtained, ranging in length from 128 to 14,540 nucleotides, of which 32 , with length $>1000$ nucleotides and mean coverage $>100$, were chosen for further analysis. Fifteen of them were attributed to the representative genome of the Adenoviridae family by taxonomic classification of nucleotide and translated protein sequences. Taxonomic classification of nucleotide and translated protein sequences was carried out using the BLAST algorithm [16] and the NCBI Taxonomy database [17]. These contigs (maximum length 14,540 nucleotides) were used to obtain whole-genome assembly using the SeqMan NGen program (DNASTAR, Madison, WI, USA).

To evaluate the assembly quality and correct possible errors, the original reads were mapped to the resulting assembly. Mapping was carried out using the BWA v.0.7.17 [18] Samtools package v.1.10 [19] was used for operations with sam/bam files. The assembly was checked for single nucleotide errors, short insertions, deletions, and breakpoints (stacks of soft-, hard-clipped reads) using Tablet program v.1.19.09.03 [20]. Separately, the quality and integrity of the $3^{\prime}$ end of the assembly were assessed.

We then used MUMmer v.3.0 [21] to verify the resulting nucleotide sequence for possible assembly artifacts. A Viral Genome Annotation System Vgas [22] was used to annotate the assembly as well as to reannotate genomes retrieved from public databases (listed below). Orthofinder v.2.5.4. was used to determine the core genome of the studied set of AdVs of various species [23]. Genes are known to have splicing were manually re-annotated as follows: (1), all possible splice sites in the TeAdV-1 genome were predicted using the BDGP Splice Site Prediction by Neural Network [24] (Supplementary Table S1); (2) in the region where the beginning of the first exon of the corresponding gene was expected (based on the analysis of genome structure of adenoviruses), all possible start codons were identified; (3) using the BioPyton library [25], all possible protein sequences were built from each start to each end of the exon of the predicted splice donor site, thenfrom the beginning of the second exon of each possible acceptor splice site to the first occurrence of the stop codon; (4) all obtained candidate-sequences were checked using BLAST search [16] and the candidate with the best "\%cover" and "identity" scores to the homologous proteins was selected.

\subsection{Phylogenetic Analysis}

The genome assemblies used in the analyses were retrieved from GenBank [26] (date of accession 17 August 2021). To build a phylogenetic tree of the representatives of the Adenoviridae family, we accessed the International Committee on Taxonomy of Viruses database (ICTV, date of accession 17 August 2021), which lists viruses that can serve as representative members of each species [2]. Sixty-three genome assemblies of different species of AdVs, chosen with the assistance of ICTV (Supplementary Table S2), were used. To build a phylogenetic tree of the representatives of the Atadenovirus genus, we used nucleotide assemblies of 25 Atadenovirus representatives with the complete genome sequence.

The multiple interspecies alignments of the 63 amino acids sequences of the 12 core proteins were performed independently in the ClustalW program [27] implemented in the MEGA-X software v.10.2.4 [28] using default settings. To eliminate poorly aligned and diverged regions, Gblocks v.0.91b [29] was used with the default parameters and the resulting fragments were concatenated. Before phylogenetic analysis, the best-fit partitioning scheme and the substitution models for each partition were determined using PartitionFinder v.2.1.1 [30] under the corrected Akaike (AICc) and the Bayesian (BIC) information criteria.

The maximum likelihood unrooted tree was generated using RAxML-NG v.1.0.2 [31]. Bootstrapping converged after 100 replicates. The obtained phylogenetic tree was rooted using the midpoint rooting method implemented in FigTree v.1.4.4 [32].

The nucleotide sequences of the genomes of 25 representatives of the genus Atadenovirus (Supplementary Table S3) were used to construct multiple interspecies alignments 
of 12 core genes. We used the nucleotide sequences of the core genes to construct the phylogeny of Atadenovirus, since we discovered resolution problems at the genus and/or species level while using protein sequences. The multiple codon alignments were performed independently as described above. Further analysis was carried out in a similar way, except for the choice of an evolutionary model. In particular, the most parameter-rich model GTR + I + G [33,34] with 12 partitions was used. The complete genome sequence of red squirrel adenovirus 1 (Squirrel mastadenovirus A, GenBank accession is KY427939.1) was used for an outgroup rooting. The trees were visualized using iTOL v.6 [35].

\subsection{Comparative Analysis}

For comparative analysis, we created pairwise alignments of (1) whole-genome sequences and (2) amino acid sequences of core genes of representative genomes of each Atadenovirus species (Supplementary Table S4) and TeAdV-1 using MAFFT [36] for every possible pair of genomes and proteins. Pairwise identity for each alignment was calculated using the AlignIO module of BioPython using DistanceCalculator from Bio.Phylo.TreeConstruction module of BioPython [25] using 'Identity' model for calculation.

\subsection{Species Delimitation}

We used three approaches that propose de novo species partitions to confirm the species status of the virus under the study. First, we used the GMYC method [37]. The GMYC is one of the most popular coalescent-based species delimitation methods, designed for single-locus data [38-40] and previously used to describe new species [41]. The method separately models the fit of Yule (pure birth; [42]) and coalescent processes [43] to an ultrametric tree to define the transition from species-level to population-level processes, used to delimit evolutionarily significant units. We used an ultrametric tree as input. The ultrametric timetree was obtained by applying the RelTime method [44,45] implemented in the MEGA-X software v.10.2.4 [28] using the GTR + I + G model [46].

We also implemented the bPTP method [37], using the maximum-likelihood phylogeny as the input tree. The bPTP method is an updated version of the original PTP with Bayesian support values. The PTP is a method that models speciation and coalescent events relative to numbers of substitutions rather than time, and uses heuristic algorithms to identify the most likely classification of branches into the population and species-level processes, used to delimit ESUs. This approach assumes either substitutions are clocklike or, if substitution rates vary across the tree, that coalescent and speciation events occur at a constant rate per substitution event, rather than per unit of time. The key advantage of the PTP, however, is that it is devised for non-ultrametric trees [37]. We ran the bPTP analysis for 500,000 steps, with default parameters.

Finally, we used ASAP [47] in default mode for species delimitation. The ASAP algorithm is an ascending hierarchical clustering, merging sequences into "groups" based on pairwise genetic distances, that are successively further merged until all sequences form a single group. A matrix of patristic distances obtained using the T-Rex web server [48] was used as input. The partition with the best asap score was selected.

Additionally, we used Birky $4 x$ index [49] to validate the species delimitation results of the two Psittacine atadenovirus $A$ strains. The method is based on the theory that random genetic drift in single species leads to the formation of clades and singlets, which descended from a common ancestor on average $2 \mathrm{Ne}$ generations ago ( $\mathrm{Ne}$ is the effective population size), and their distance from each other will be less than $2 \mathrm{Ne}$ generations. Alternatively, as a result of the speciation process, a species is divided into completely separated populations, which form clusters separated by a gap exceeding $2 \mathrm{Ne}$. According to the $4 \times$ rule, clusters separated by $\mathrm{t} \geq 4 \mathrm{Ne}$ generations are characterized by a probability of less than $5 \%$ that the clusters were formed as a result of random genetic drift. Unfortunately, the Birky index cannot be applied to species delimitation of clades, at least one of which contains only one sequence, because it becomes impossible to calculate intra-clade distances. 


\subsection{Codon-Based Analysis of Positive Selection}

The analysis of possible recombination events was performed using the GARD program [50] implemented in the HyPhy software v.2.5 [51].

To examine the impact of pervasive positive selection on the set of adenoviral core genes in the genomes of Atadenovirus representatives, we used both the CODEML program as implemented in PAML software package v.4.9 [52] and the FEL method [53] as implemented in HyPhy software package v.2.5 [51]. Site models (M8 and M8a) were executed in CODEML, and then statistical likelihood ratio tests (LRT) were performed to evaluate adaptive evolution acting at particular sites along all lineages of the phylogenetic tree. When the LRT was significant, the codons that were likely to evolve under positive selection based on PP thresholds of 0.7 and 0.95 were filtered out. Further, to obtain reliable analysis results, we found an intersection between statistically significant sites acquired using both methods. The conversion of the codon coordinates of the alignment, consisting of concatenated blocks, back to the original coordinates of the amino acid sites of proteins was performed using a custom Python script.

To examine the impact of episodic positive selection on the set of adenoviral core genes in the TeAdV-1 genome, we used both the CODEML program as implemented in the PAML software package v.4.9 [52] and BS-REL approach as implemented in HyPhy software package v.2.5 [51]. We used a branch-site likelihood method known as test 2 which is recommended by the authors as a direct test for positive selection at the molecular level [54]. Branch-site models (null and alternative, which are A1 and A respectively in CODEML) were executed and then statistical likelihood ratio tests (LRT) for evaluating adaptive evolution in the linage of interest were conducted. Filtration and the intersection of statistically significant sites occurred according to the pipeline described above.

\subsection{Protein 3D Structure Prediction}

To model 3D structures of TeAdV-1 proteins we used AlphaFold2 [55] with Uniref90, Mgnify, BFD, UniClust30, and pdb70 databases. The prediction for each protein comprised of 5 relaxed models, 5 unrelaxed models, and 5 resulting models. All models were compared with each other using the "match maker" function of UCSF Chimera [56] to evaluate the uniformity of predictions. We used the capsid structure of lizard adenovirus 2 [57] and human adenovirus 41 [58] as templates for capsid structures modeling. Visualization for all individual proteins and structures was performed using UCSF Chimera [56].

\section{Results}

\subsection{Genome of TeAdV-1 and Comparative Analyses}

Tern atadenovirus 1 (TeAdV-1) genome is a linear double-stranded DNA molecule, 31,334 base pairs in length. The genome shows typical for AdVs structure and has 30 methionine-initiated open reading frames (ORFs), 22 of which were identified as proteincoding genes by comparative analysis of homologs protein sequences. Similar to other AdVs, TeAdV-1 contains a conservative set of genes located at the central part of the genome and species-specific end (Figure 1, Table 1). We identified the entire set of genes conserved for the Adenoviridae family, as well as genus-specific genes typical for Atadenovirus and 8 additional ORFs, the set of which is unique for TeAdV-1. Genes known to have splicing were manually annotated using predicted splice sites (Supplementary Table S2).

The coding region is surrounded by inverted terminal repeats (ITR), consisting of 25 bases with the coordinates of 1-25 sense orientation and 31,310-31,334 antisense orientation. To date, it is the shortest known ITR region within the Atadenovirus genus to the best of our knowledge and one of the shortest within all Adenoviridae family [60], closest by length to the Siadenovirus representatives (Supplementary Table S5).

The nucleotide composition of the genome is characterized by a low $\mathrm{G}+\mathrm{C}$ content$33.86 \%$, which is more inherent in ruminant viruses than avian ones (Figure 2). However, the nucleotide sequence of the TeAdV-1 genome shows the closest resemblance to the duck atadenovirus 1 (KJ452172.1, Duck atadenovirus $A$ ) with identity 53.7\% (Figure 2). 


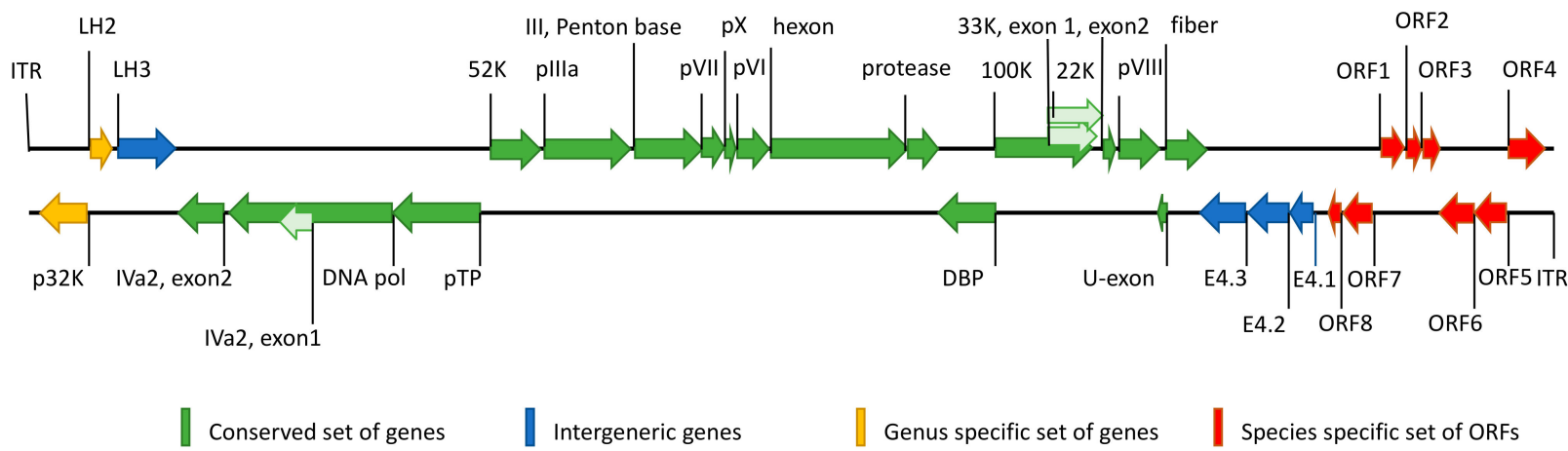

Figure 1. Schematic view of the TeAdv-1 genome structure. Genes and ORFs are illustrated as arrows pointing in the direction of transcription. Green indicates a conserved set of genes present in the genomes of AdVs. Genes that are found in the genomes of more than one genus of AdVs, including the genus Atadenovirus, are shown in blue. Genes specific to Atadenovirus are highlighted in yellow. Specific for TeAdV-1 genes colored red.

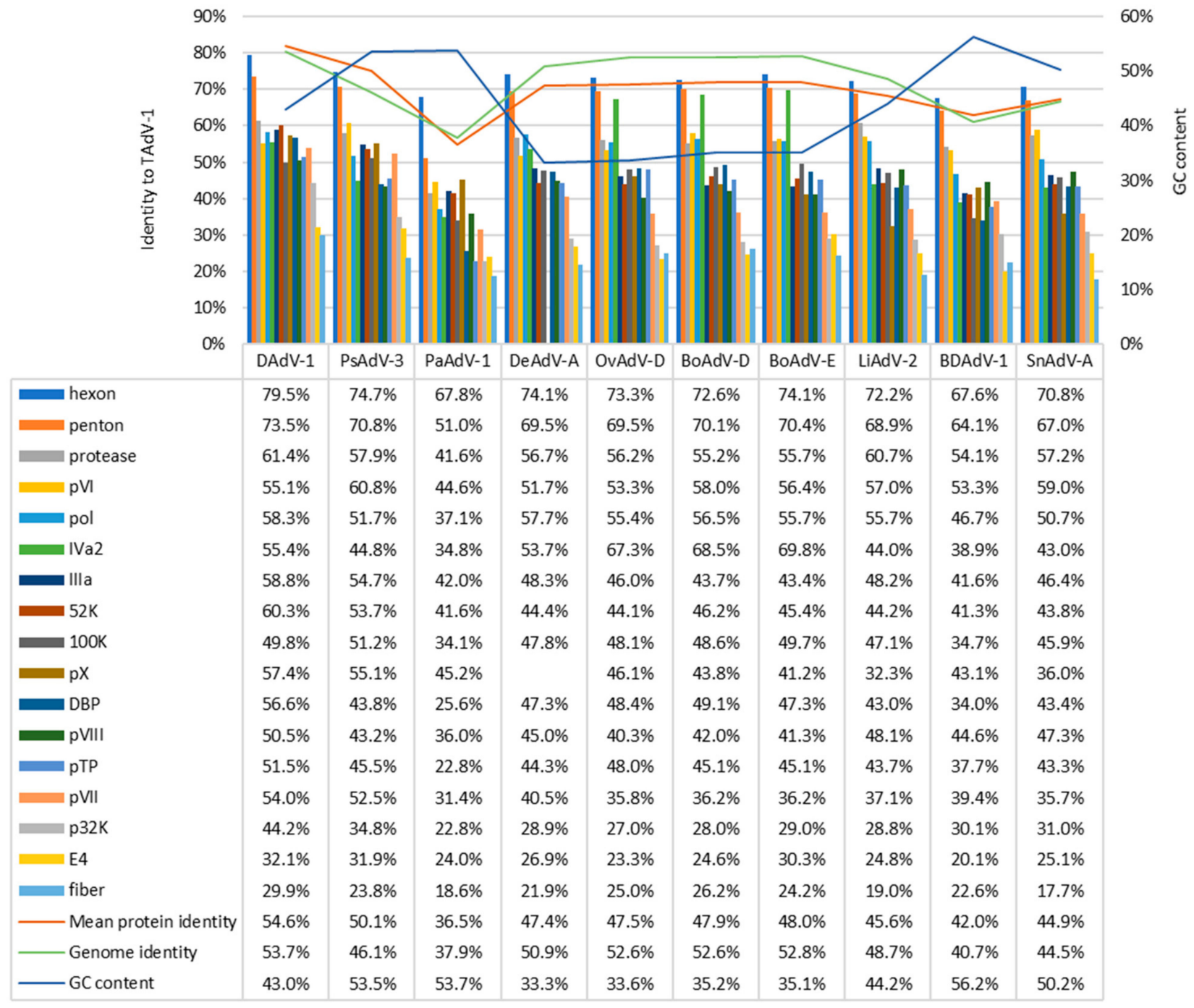

Figure 2. Comparison of TeAdV-1 genome with genomes of other members of Atadenovirus genus. Colored bars represent the degree of pairwise identity of specific proteins conservative within Adenoviridae family and Atadenovirus genus, colored lines represent mean protein and genomic sequence identity across all genes as well as mean GC content. 
Table 1. Predicted protein-coding genes and methionine-initiated ORFs of TeAdV-1 and syntenic genes of phylogenetically closely related duck adenovirus 1 (DAdV-1) [4] and psittacine adenovirus 3 (PsAdV-3) [59].

\begin{tabular}{|c|c|c|c|c|c|c|}
\hline TeAdV-1 & \multicolumn{2}{|c|}{ Gene } & \multirow{2}{*}{$\frac{\text { Strand }}{-}$} & \multirow{2}{*}{$\begin{array}{c}\text { Size (aa) } \\
312\end{array}$} & \multirow{2}{*}{$\begin{array}{r}\text { DAdV-1 } \\
\text { p32 K }\end{array}$} & \multirow[t]{2}{*}{ PsAdV-3 } \\
\hline p32 K & 236 & 1174 & & & & \\
\hline LH2 & 1209 & 1625 & + & 138 & LH2 & E1B protein, small T-antigen \\
\hline LH1 & 1656 & 2804 & + & 382 & E1B $55 \mathrm{~K}$ & \\
\hline \multirow{2}{*}{ IVa2 protein } & 2875 & 3696 & \multirow{2}{*}{-} & \multirow{2}{*}{296} & \multirow{2}{*}{ IVa2 protein } & \multirow{2}{*}{ IVa2 protein } \\
\hline & 4614 & 4682 & & & & \\
\hline DNA polymerase & 3945 & 7181 & - & 1078 & DNA polymerase & DNA polymerase \\
\hline \multirow{2}{*}{ pTP } & 7157 & 8950 & \multirow{2}{*}{-} & \multirow{2}{*}{602} & \multirow{2}{*}{ pTP } & \multirow{2}{*}{ pTP } \\
\hline & 11680 & 11694 & & & & \\
\hline $52 \mathrm{~K}$ protein & 8985 & 9971 & + & 328 & $52 \mathrm{~K}$ protein & $52 \mathrm{~K}$ protein \\
\hline pIIIa protein & 9955 & 11664 & + & 569 & pIIIa protein & pIIIa protein \\
\hline penton base protein & 11704 & 13062 & + & 452 & penton base protein & penton base protein \\
\hline pVII protein & 13104 & 13559 & + & 151 & $\mathrm{pVII}$ & pVII \\
\hline $\mathrm{pX}$ protein & 13568 & 13765 & + & 65 & $\mathrm{pX}$ & $\mathrm{pX}$ \\
\hline pVI protein & 13800 & 14435 & + & 211 & $\mathrm{pVI}$ & $\mathrm{pVI}$ \\
\hline hexon protein & 14456 & 17188 & + & 910 & hexon protein & hexon protein \\
\hline protease & 17185 & 17790 & + & 201 & protease & protease \\
\hline DNA-binding protein & 17809 & 18951 & - & 380 & DNA-binding protein & DNA-binding protein \\
\hline $100 \mathrm{~K}$ protein & 19005 & 20924 & + & 639 & $100 \mathrm{~K}$ protein & $100 \mathrm{~K}$ protein \\
\hline $22 \mathrm{~K}$ protein & 20758 & 20982 & + & 75 & & \\
\hline \multirow{2}{*}{$33 \mathrm{~K}$ protein } & 20758 & 20973 & \multirow{2}{*}{+} & \multirow{2}{*}{150} & \multirow{2}{*}{$33 \mathrm{~K}$ protein } & \multirow{2}{*}{$33 \mathrm{~K}$ protein } \\
\hline & 21059 & 21292 & & & & \\
\hline pVIII protein & 21323 & 22129 & + & 268 & pVIII protein & pVIII protein \\
\hline U-exon & 22142 & 22306 & - & 54 & U-exon & U-exon \\
\hline fiber protein & 22324 & 24369 & + & 681 & fiber protein & fiber 2 protein \\
\hline E4.3 protein & 24383 & 25273 & - & 296 & $34 \mathrm{~K}-2$ & E4.3 protein \\
\hline E4.2 protein & 25221 & 26027 & - & 268 & $34 \mathrm{~K}-1$ & E4.2 protein \\
\hline E4.1 protein & 25948 & 26385 & - & 145 & & E4.1 protein \\
\hline ORF8 & 26628 & 26870 & - & 80 & & \\
\hline ORF7 & 26888 & 27451 & - & 187 & & \\
\hline ORF1 & 27508 & 27966 & + & 152 & & \\
\hline ORF2 & 28072 & 28359 & + & 95 & & \\
\hline ORF3 & 28366 & 28698 & + & 110 & & \\
\hline ORF6 & 28872 & 29558 & - & 228 & & \\
\hline ORF5 & 29658 & 30296 & - & 212 & & \\
\hline ORF4 & 30424 & 31146 & + & 240 & & \\
\hline
\end{tabular}


In general, the primary structure of proteins encoded by genes of the conserved region of the genome shows the maximum identity with DAdV-1, with the exception of the IVa2 protein, which is significantly more similar to ruminant viruses of the Atadenovirus genus (with an identity score being $10 \%$ higher), the $\mathrm{pVI}$ protein sequence of which appears to be closer to psittacine atadenovirus 3 (PsAdV-3, identity 5\% higher), and $100 \mathrm{~K}$ protein which is also slightly more similar to PsAdV-3 (about $1 \%$ higher). Atadenovirus specific p32 K protein exhibited relatively low similarity ranging between 44 and $23 \%$ when calculated by an amino acid sequence where the highest identity score was also with DAdV-1. The most divergent protein was fiber with the highest identity to DAdV-1 $(\sim 30 \%)$ wheres conservative capsid proteins-penton base and hexon demonstrated the highest identity scores among all protein sequences: $79.5 \%$ and $73.5 \%$ to DAdV-1 respectively (Figure 2).

In the TeAdV-1 genome, we found three E4 genes (E4.1, E4.2, and E4.3). E4.2 and E4.3 proteins showed the highest similarity to the DAdV-1 proteins (pairwise identity 35.3 and $30.7 \%$ accordingly), whereas E4.1 protein was most similar with PsAdV-1 gene E4.1 with $29.1 \%$ amino acid sequence identity.

The variable region of the TeAdV-1 genome contains eight ORFs, 7 of which have sequence homology to ones found in other characterized Atadenovirus representatives. We have found homologs to hypothetical protein sequences for ORF1, 2, 3, and 7 in DAdV-1 and for ORF4, 5, 6 in PsAdV-3 with identity varies between 28 and 44\% for different ORFs (Supplementary Table S6). ORF8 was not found among predicted protein sequences of other Atadenovirus species by blast search. ORF8 encodes short protein 80 amino acids in length, which appears to be unique for TAdV1 and consists of two alpha-helixes, connected with turn motif (HTH-motif).

\subsection{Evolutionary Relationships of TAdV-1}

In order to establish the relationship between TeAdV- 1 and other members of the Adenoviridae family, we carried out a phylogenetic analysis. We used aligned concatenated sequences of core genes to build a phylogenetic tree. The use of sequences of concatenated genes as opposed to the use of sequences of individual genes increased the statistical power of the molecular evolution analysis and improved the accuracy of the obtained phylogenetic tree since a higher number of substitutions is analyzed. We constructed an Adenoviridae phylogenetic tree based on the concatenated amino acid sequences of the 12 core proteins that were found to be encoded in the genomes of all analyzed representatives of the family. The list of the core genes used for phylogenetic reconstruction and their annotations are presented in Table 2. Fiber protein was excluded from the set of core genes due to the low consistency of multiple sequence alignment arising from a high level of divergence of this protein.

The external nodes of the obtained phylogenetic tree were strongly supported by bootstrap values and, regardless of the slight differences, accurately reproduced the existing robust phylogenies of adenoviruses (Figure 3).

Genome TeAdV-1 is located within the clade of the phylogenetic tree corresponding to the Atadenovirus genus. Based on the nucleotide sequences of the core genes, we constructed a phylogenetic tree of the Atadenovirus genus with a higher resolution (Figure 4).

For the species delimitation, we used several approaches. We used Assemble Species by Automatic Partitioning (ASAP) method to build species partitions from pairwise patristic genetic distances. As a result of using this method, the studied set of 27 Atadenovirus representatives was divided into 9 partitions corresponding to different species (Table 3). The obtained result demonstrates that the TeAdV-1 genome does not enter the partition together with other genomes. In addition, we used the bPTP web interface that delimits species based on the Phylogenetic Species Concept. We obtained the same result based on both the maximum likelihood and Bayesian approaches. Using both approaches, 11 species partitions were identified. In both cases, the TeAdV-1 forms an independent operational taxonomic unit. Finally, we applied the GMYC method. Twelve species groups were 
identified using a single-threshold approach and 8 species using a multiple-threshold approach (Table 3).

Table 2. The list of the core genes of the adenoviruses is determined based on the analysis of groups of orthologous genes of the studied set of genomes of the type representatives of the family.

\begin{tabular}{ll}
\hline \multicolumn{1}{c}{ Gene } & \multicolumn{1}{c}{ Annotation } \\
\hline $100 \mathrm{~K}$ protein & $\begin{array}{l}\text { participation in the transport of hexon monomers to the nucleus and } \\
\text { trimerization [61] }\end{array}$ \\
\hline $23 \mathrm{~K}$ protein (endopeptidase, protease) & participation in the cleavage of some AdV precursor proteins [62,63] \\
\hline 52 K protein & participation in the packaging of the viral DNA into the capsid [62,63] \\
\hline DBP (DNA-binding protein) & $\begin{array}{l}\text { participation in the elongation phase of AdV DNA replication by } \\
\text { unwinding the template [64] }\end{array}$ \\
\hline hexon & major capsid protein $[62,63]$ \\
\hline III (penton base) & major capsid protein $[62,63]$ \\
\hline pIIIa & minor capsid protein $[62,63,65]$ \\
\hline IVa2 & participation in the packaging of the viral DNA into the capsid [62,63] \\
\hline Pol (DNA polymerase) & participation in the elongation phase of AdV DNA replication [64] \\
\hline pTP (preterminal protein) & the protein primer for AdV DNA replication [64] \\
\hline pVI & minor capsid protein $[62,63,65]$ \\
\hline pVIII & minor capsid protein $[62,63,65]$ \\
\hline
\end{tabular}

Table 3. Species delimitation schemes were obtained using the ASAP, PTP and GMYC approach. The following abbreviations are used: Bovine adenovirus $F$ (BoAdV-F), Ovine atadenovirus D (OvAdV-D), Deer atadenovirus $A$ (OdAdV-A), Bovine atadenovirus $D$ (BoAdV-D), Bovine atadenovirus $E$ (BoAdV-E), Lizard atadenovirus B (LiAdV-B), Lizard atadenovirus A (LiAdV-A), Psittacine atadenovirus A (PsAdV-A), Duck atadenovirus $A$ (DAdV-A). The last row contains the total number of partitions obtained when analyzing 26 representatives of the Atadenovirus genus.

\begin{tabular}{llll}
\hline \multicolumn{1}{c}{ ASAP } & \multicolumn{1}{c}{ PTP } & \multicolumn{1}{c}{$\begin{array}{c}\text { GMYC } \\
\text { (Single-Threshold) }\end{array}$} & $\begin{array}{c}\text { GMYC } \\
\text { (Multiple-Threshold) }\end{array}$ \\
\hline TAdV-1 & TAdV-1 & TAdV-1 & TAdV-1 \\
\hline LC606503.1 & LC606503.1 & LC606503.1 & LC606503.1 \\
BoAdV-F & BoAdV-F & BoAdV-F & BoAdV-F \\
LC597488.1 & LC597488.1 & LC597488.1 & LC597488.1 \\
BoAdV-F & BoAdV-F & BoAdV-F & BoAdV-F \\
MN901942.2 & MN901942.2 & MN901942.2 & MN901942.2 \\
BoAdV-F & BoAdV-F & BoAdV-F & BoAdV-F \\
\hline U40839.3 & U40839.3 & U40839.3 & U40839.3 \\
OvAdV-D & OvAdV-D & OvAdV-D & OvAdV-D \\
\hline
\end{tabular}


Table 3. Cont.

\begin{tabular}{|c|c|c|c|}
\hline ASAP & PTP & $\begin{array}{c}\text { GMYC } \\
\text { (Single-Threshold) }\end{array}$ & $\begin{array}{c}\text { GMYC } \\
\text { (Multiple-Threshold) }\end{array}$ \\
\hline MK537328.1 & MK537328.1 & MK537328.1 & MK537328.1 \\
\hline OdAdV-A & OdAdV-A & OdAdV-A & OdAdV-A \\
\hline KY748210.1 & KY748210.1 & KY748210.1 & KY748210.1 \\
\hline OdAdV-A & OdAdV-A & OdAdV-A & OdAdV-A \\
\hline KY468403.1 & KY468403.1 & KY468403.1 & KY468403.1 \\
\hline OdAdV-A & OdAdV-A & OdAdV-A & OdAdV-A \\
\hline KY468402.1 & KY468402.1 & KY468402.1 & KY468402.1 \\
\hline OdAdV-A & OdAdV-A & OdAdV-A & OdAdV-A \\
\hline MK343439.1 & MK343439.1 & MK343439.1 & MK343439.1 \\
\hline OdAdV-A & OdAdV-A & OdAdV-A & OdAdV-A \\
\hline KY468406.1 & KY468406.1 & KY468406.1 & KY468406.1 \\
\hline OdAdV-A & OdAdV-A & OdAdV-A & OdAdV-A \\
\hline KY468407.1 & KY468407.1 & KY468407.1 & KY468407.1 \\
\hline OdAdV-A & OdAdV-A & OdAdV-A & OdAdV-A \\
\hline KY468404.1 & KY468404.1 & KY468404.1 & KY468404.1 \\
\hline OdAdV-A & OdAdV-A & OdAdV-A & OdAdV-A \\
\hline KY468405.1 & KY468405.1 & KY468405.1 & KY468405.1 \\
\hline OdAdV-A & OdAdV-A & OdAdV-A & OdAdV-A \\
\hline \multirow{4}{*}{$\begin{array}{l}\text { AF036092.3 } \\
\text { BoAdV-D } \\
\text { JQ345700.1 } \\
\text { BoAdV-E }\end{array}$} & AF036092.3 & \multirow{4}{*}{$\begin{array}{l}\text { AF036092.3 } \\
\text { BoAdV-D } \\
\text { JQ345700.1 } \\
\text { BoAdV-E }\end{array}$} & AF036092.3 \\
\hline & BoAdV-D & & BoAdV-D \\
\hline & JQ345700.1 & & JQ345700.1 \\
\hline & BoAdV-E & & BoAdV-E \\
\hline MT050041.1 & МT050041.1 & MT050041.1 & MT050041.1 \\
\hline LiAdV-B & LiAdV-B & LiAdV-B & LiAdV-B \\
\hline KJ156523.1 & KJ156523.1 & KJ156523.1 & KJ156523.1 \\
\hline LiAdV-A & LiAdV-A & LiAdV-A & LiAdV-A \\
\hline \multirow{4}{*}{$\begin{array}{l}\text { KJ675568.1 } \\
\text { PsAdV-A } \\
\text { MN025529.1 } \\
\text { PsAdV-A }\end{array}$} & KJ675568.1 & \multirow{4}{*}{$\begin{array}{l}\text { KJ675568.1 } \\
\text { PsAdV-A } \\
\text { MN025529.1 } \\
\text { PsAdV-A }\end{array}$} & KJ675568.1 \\
\hline & PsAdV-A & & PsAdV-A \\
\hline & MN025529.1 & & MN025529.1 \\
\hline & PsAdV-A & & PsAdV-A \\
\hline KJ452170.1 & KJ452170.1 & KJ452170.1 & KJ452170.1 \\
\hline DAdV-A & DAdV-A & DAdV-A & DAdV-A \\
\hline KJ452171.1 & KJ452171.1 & KJ452171.1 & KJ452171.1 \\
\hline DAdV-A & DAdV-A & DAdV-A & DAdV-A \\
\hline \multirow{8}{*}{$\begin{array}{l}\text { KF286430.1 } \\
\text { DAdV-A } \\
\text { KJ452172.1 } \\
\text { DAdV-A } \\
\text { MT646045.1 } \\
\text { DAdV-A } \\
\text { MN310513.1 } \\
\text { DAdV-A }\end{array}$} & \multirow{8}{*}{$\begin{array}{l}\text { KF286430.1 } \\
\text { DAdV-A } \\
\text { KJ452172.1 } \\
\text { DAdV-A } \\
\text { MT646045.1 } \\
\text { DAdV-A } \\
\text { MN310513.1 } \\
\text { DAdV-A }\end{array}$} & \multirow{8}{*}{$\begin{array}{l}\text { KF286430.1 } \\
\text { DAdV-A } \\
\text { KJ452172.1 } \\
\text { DAdV-A } \\
\text { MT646045.1 } \\
\text { DAdV-A } \\
\text { MN310513.1 } \\
\text { DAdV-A }\end{array}$} & KF286430.1 \\
\hline & & & DAdV-A \\
\hline & & & KJ452172.1 \\
\hline & & & DAdV-A \\
\hline & & & MT646045.1 \\
\hline & & & DAdV-A \\
\hline & & & MN310513.1 \\
\hline & & & DAdV-A \\
\hline 9 & 11 & 8 & 14 \\
\hline
\end{tabular}




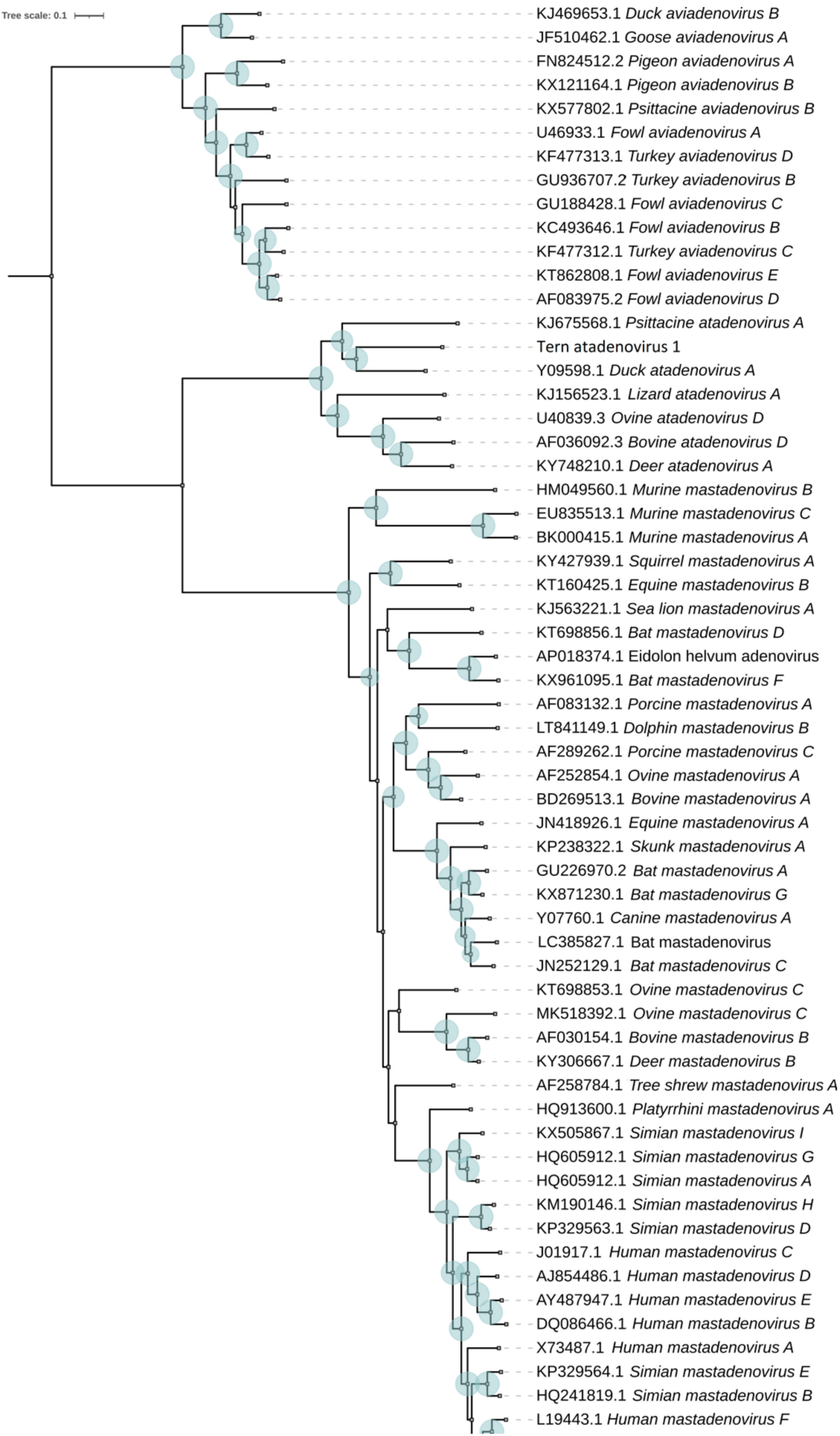

Figure 3. Maximum likelihood phylogenetic tree based on concatenated amino acid sequences of the 12 core proteins of 63 representatives of various species of the Adenoviridae family after 100 bootstrap replicates. Bootstrap values higher than 70 are marked next to the respective nodes (blue circles) showing a robust phylogenetic reconstruction. 


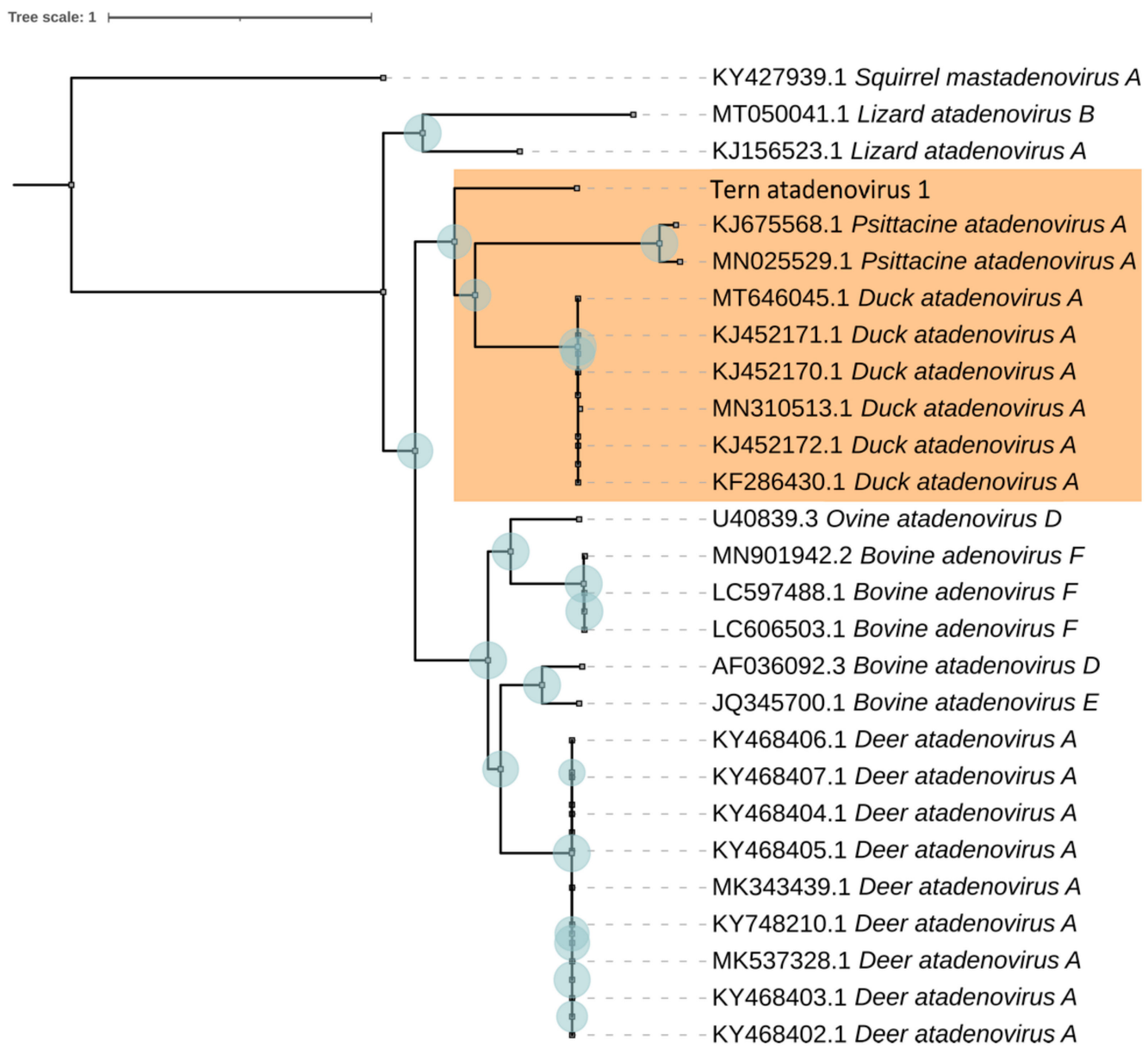

Figure 4. Maximum likelihood phylogenetic tree based on concatenated amino acid sequences of the 12 core proteins of 29 representatives of various species of the Atadenovirus genus after 1000 bootstrap replicates. Bootstrap values higher than 70 are marked next to the respective nodes (blue circles) showing a robust phylogenetic reconstruction. A clade of related species of avian viruses of the Atadenovirus genus is indicated (orange box).

Thus, we have shown that the genome we are studying belongs to a new type of atadenovirus, and is not a strain of a previously sequenced or described species.

It is noteworthy that different methods delimit two Psittacine atadenovirus $A$ strains differently. Therefore, we used an additional method (Birky $4 \times$ rule) that also confirmed that the strains KJ675568.1 [59] and MN025529.1 [66] are different species.

\subsection{Protein Prediction}

We predicted 3D structures for DNA-polymerase, penton base, hexon, fiber, E1B large subunit, and E1B small subunit, using AlphaFold2. To evaluate uniformity between models predicted by AlphaFold2 we performed structural comparison using MatchMaker of UCSF Chimera. All domains of predicted proteins were highly similar in all models, apart from side chains, whose structures could not be predicted without information on protein-protein interactions (Figures 5 and 6). Considering all of the above for fiber model comparison could be performed only for the head domain, as full protein could not be modeled with sufficient uniformity and precision as a monomer. 


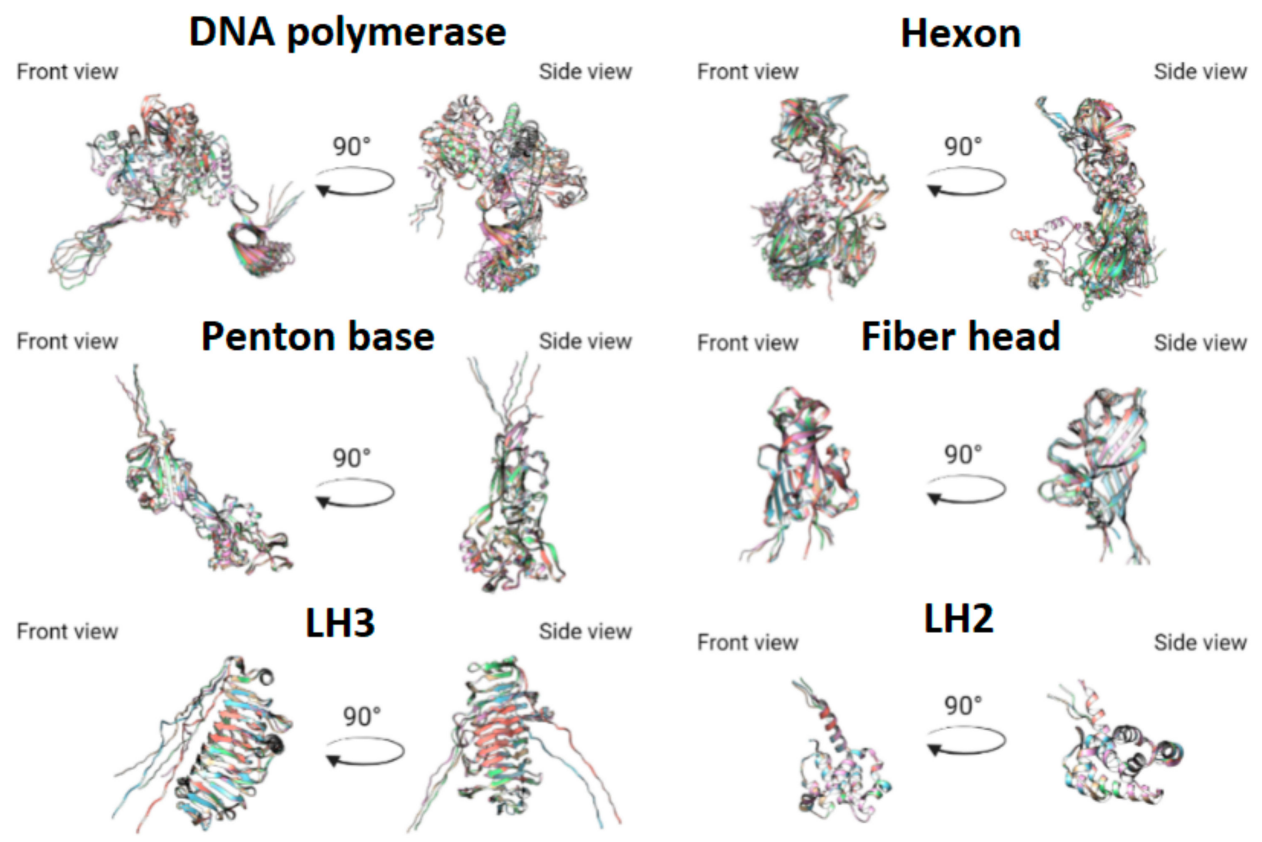

Figure 5. Comparison for predicted proteins 3D structures. For convenience, different colors were used for each predicted structure.
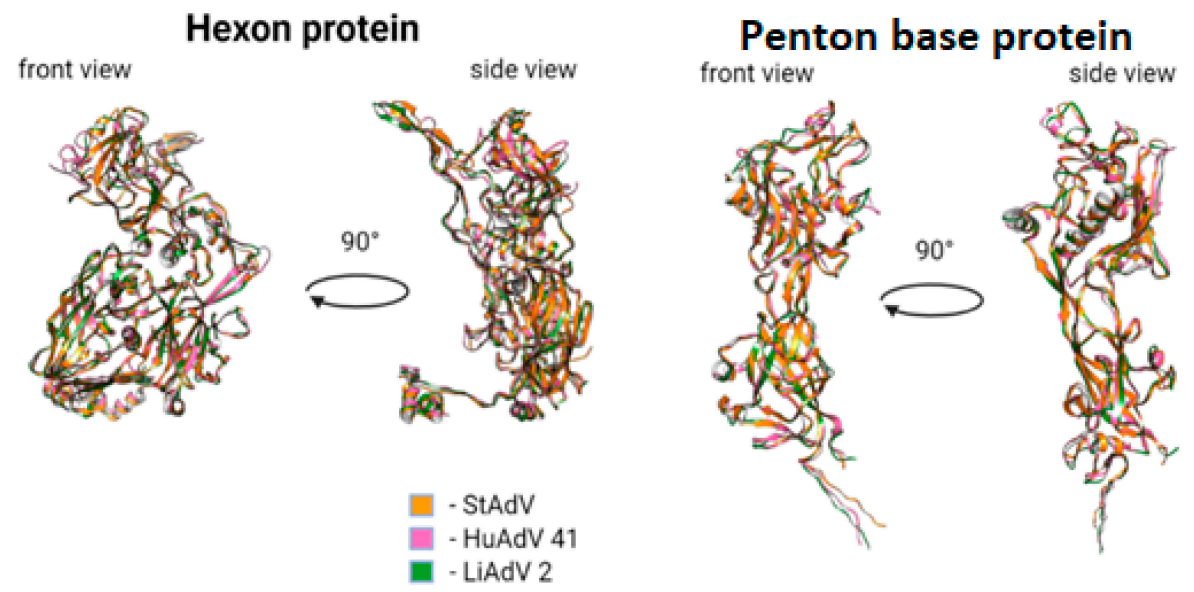

Figure 6. Predicted 3D structure of hexon and penton base proteins, compared to hexon and penton base proteins of HAdV-41 and LAdV-2.

We also compared hexon and penton base with corresponding proteins of lizard adenovirus 2 (LAdV-2) [57] and human adenovirus 41 (HAdV-41) [58]. All motifs were conserved between all species with minor differences. For penton base protein we demonstrated the following differences:

1. Absence of alpha-helix, corresponding to Tyr288-Val285 in HAdV-41, lacking in TAdV, lacking in LAdV-2;

2. Elongation of alpha-helix Val138-Asn159 (21 aa) in TAdV, which corresponds to Glu173-Ala183 (10 aa) in HAdV-41 and Val138-Gly157 (19 aa) in LAdV-2;

3. Presence of beta-sheet-like short structure at Gly208-Asp210 in TAdV, lacking in HAdV-41 and LAdV-2 alike.

4. TAdV alpha-helix Thr41-Ser46, presented in HAdV-41 as Asn72-Ala75, lacking in LAdV-2.

5. Presence of structure Val233-Leu235 beta-sheet to Tyr236-Ile239 alpha helix, presented in StAdV which is absent in HAdV-41 and LAdV-2.

For hexon we demonstrated the following differences: 
1. Presence of two beta-sheets $\mathrm{Glu}^{380}{ }_{-} \mathrm{Gly}^{382}, \mathrm{Ala}^{400}-\mathrm{Ile}^{402}$, absent in HAdV-41 and LAdV-2;

2. Elongation of beta-sheet $\mathrm{Gln}^{816}-\mathrm{Cys}^{824}$ (8 aa), corresponding to $\mathrm{Val}^{816}-\mathrm{Val}^{823}$ (7 aa) in LAdV-2 and Ser ${ }^{831}$-Lys $^{836}$ (5 aa)

3. Presence of beta-sheet Gln ${ }^{229}$ Leu $^{233}$, absent in LAdV-2 and HAdV-41.

4. Elongation of beta-sheet $\operatorname{Ser}^{187}-\mathrm{Ile}^{197}$ (10 aa), corresponding to $\operatorname{Arg}^{201}-\mathrm{Ile}^{203}$ (2 aa) in HAdV-41 and absent in LAdV-2

5. Presence of alpha-helix Val ${ }^{153}$-Lys ${ }^{157}$, absent in HAdV-41 and LAdV-2.

6. Elongation of beta-sheet $\mathrm{Cys}^{269}-\mathrm{Gly}^{273}$ (4 aa), corresponding to $\operatorname{Arg}^{263}-\mathrm{Thr}^{265}$ (2 aa) in LAdV-2 and absent in HAdV-41.

We used the capsid structure of lizard adenovirus 2 [57] and human adenovirus 41 [58] as templates for capsid structures modeling. We used UCSF Chimera MatchMaker to predict the 3D structure of TAdV capsid monomer, which consists of 4 hexon trimers in a diamond shape, penton base protein, 1 LH3 trimer, 1 LH3 monomer, pIIIa, pVIII, pVI, and pVII proteins, which is commonly referred to as icosahedral asymmetric unit (AU) (Figure 7) [57].
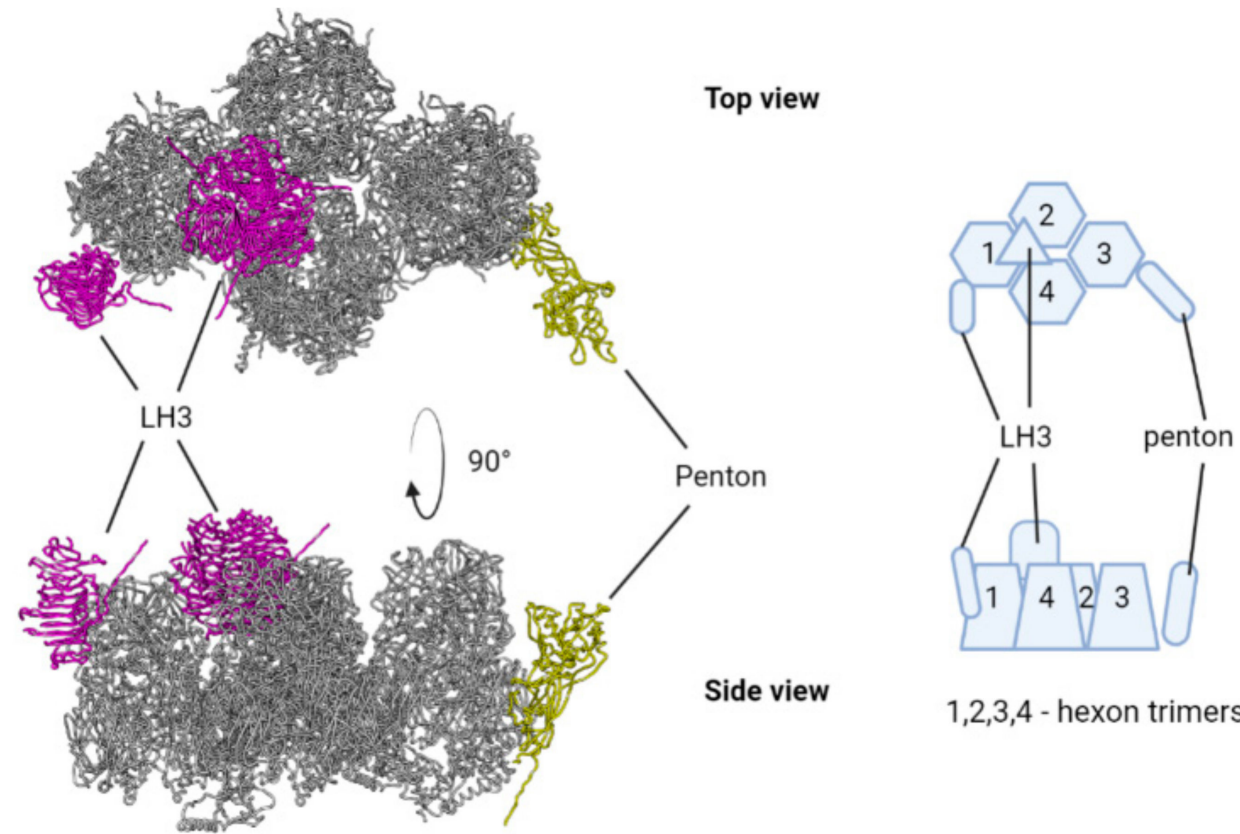

$1,2,3,4$ - hexon trimers

Figure 7. Icosaedral asymmetric unit (AU) of TAdV, penton base, and LH3 proteins are highlighted with color.

\subsection{Detection of Adaptive Evolution Events}

Since recombination is known to produce false-positive results [67], we screened the sequences for recombination events before running the positive selection tests. We found no evidence of recombination in the sequences studied. Then the analysis of molecular evolution was carried out using the method of maximum likelihood that allows for the detecting evolutionary events of pervasive or episodic positive selection in the nucleotide sequences of protein-coding genes.

\subsubsection{Pervasive Positive Selection in the Molecular Evolution of Atadenovirus}

First, we tested the hypothesis for the presence of pervasive positive selection events in the molecular evolution of the adenoviral core genes. We obtained values of the loglikelihood function for the site models M8 and M8a using the CODEML program and then we conducted LRT for the presence of sites under positive selection pressure $(\omega>1)$ in all branches of the phylogenetic tree of Atadenovirus. The LRT value for the test was statistically significant (LRT $=67.265, p<<0.01$ ). Thus, in silico analysis showed that there is 
evidence for sites under the pressure of positive selection in all branches of the phylogenetic tree of Atadenovirus built on the basis of concatenated sequences of the adenoviral core genes. Then the specific sites were identified using the Bayes empirical Bayes (BEB) approach [43]. Sites with a posterior probability $(P P) \geq 0.7$ were inferred to have evolved under positive selection. We found 7 positive selected sites with $P P \geq 0.7$ in the genes encoding Pol, pTP, and III (penton base) (Supplementary Table S7). To test the robustness of our results, we used a complementary approach. We found pervasive positive selection events using the FEL method, which is consistent with our previous results. We found 10 sites under positive diversifying selection at $p \leq 0.1$ in the genes encoding Pol, DBP, pIIIa (Supplementary Table S8).

\subsubsection{Episodic Positive Selection in the Molecular Evolution of TAtV-1}

Episodic selection affecting individual sites in individual branches and clades of a phylogenetic tree is the most common case of positive selection. We tested the hypothesis that there are sites under the pressure of positive selection $(\omega>1)$ in the tested branch compared to the other branches of the phylogeny. We obtained values of the log-likelihood function for two branch-site models A1 and A for the TeAdV-1 branch of the phylogenetic tree of Atadenovirus using the CODEML program, and then we applied LRT test 2 which was developed by the authors as a direct testing method for the detection of positive selection in the lineages of interest [40]. The LRT value for the test was statistically significant (LRT $=73.857, p<<0.01$ ). Thus, in silico analysis proved the presence of episodic positive selection events in the molecular evolution of the adenoviral core genes in the TeAdV-1 branch of the phylogenetic tree of Atadenovirus. We found 153 positive selected sites with $P P \geq 0.7$. Again, the additional program was used to verify the obtained results. BS-REL models (null and alternative) were executed using HyPhy software. The LRT value for the test 2 was statistically significant (LRT $=12.907, p<<0.01$ ). We detected 151 positive selected sites with $P P \geq 0.7$. Eighty-six sites matched those previously predicted using CODEML (Supplementary Table S9). Sites with $P P$ values $\geq 0.95$ were inferred to be the most reliable candidates for positive selection (Table 4).

Candidate sites for positive selection, marked on the predicted 3D structures of the corresponding proteins, can be found in the supplementary material (Supplementary Figure S1).

Table 4. Identified the most reliable candidate sites for positive selection. $P P$ values $\geq 0.95$ are in bold.

\begin{tabular}{cccc}
\hline \multirow{2}{*}{ Protein } & $\begin{array}{c}\text { Amino Acid } \\
\text { Coordinate }\end{array}$ & $\boldsymbol{P P}$ (CODEML) & $\begin{array}{c}\text { PP } \\
\text { (HyPhy) }\end{array}$ \\
\hline & 118 & 0.886 & $\mathbf{0 . 9 6 2}$ \\
\cline { 2 - 4 } 100 K protein & 230 & 0.807 & $\mathbf{0 . 9 5 1}$ \\
\cline { 2 - 4 } & 450 & 0.905 & $\mathbf{0 . 9 7 2}$ \\
\cline { 2 - 4 } & 96 & 0.87 & $\mathbf{0 . 9 7 2}$ \\
\cline { 2 - 4 } & 13 & 0.903 & $\mathbf{0 . 9 5 5}$ \\
\cline { 2 - 4 } & 162 & 0.904 & $\mathbf{0 . 9 5 0}$ \\
\hline
\end{tabular}


Table 4. Cont.

\begin{tabular}{|c|c|c|c|}
\hline Protein & $\begin{array}{l}\text { Amino Acid } \\
\text { Coordinate }\end{array}$ & PP (CODEML) & $\begin{array}{c}\text { PP } \\
\text { (HyPhy) }\end{array}$ \\
\hline \multirow{4}{*}{ pIVa2 } & 123 & 0.937 & 0.983 \\
\hline & 137 & 0.894 & 0.982 \\
\hline & 152 & 0.946 & 0.971 \\
\hline & 94 & 0.935 & 0.964 \\
\hline \multirow{4}{*}{ DNA polymerase } & 1044 & 0.862 & 0.951 \\
\hline & 366 & 0.934 & 0.973 \\
\hline & 367 & 0.927 & 0.962 \\
\hline & 773 & 0.941 & 0.961 \\
\hline \multirow{9}{*}{ pTP } & 145 & 0.85 & 0.961 \\
\hline & 187 & 0.946 & 0.966 \\
\hline & 297 & 0.859 & 0.975 \\
\hline & 405 & 0.926 & 0.952 \\
\hline & 44 & 0.946 & 0.972 \\
\hline & 445 & 0.939 & 0.966 \\
\hline & 565 & 0.795 & 0.950 \\
\hline & 89 & 0.93 & 0.966 \\
\hline & 96 & 0.939 & 0.988 \\
\hline
\end{tabular}

\section{Discussion}

With this paper, we describe the first complete genome of tern adenovirus TeAdV-1, obtained from a bird Sterna hirundo.

The genome structure of TeAdV- 1 corresponds to the general scheme of the genomes of AdVs: dsDNA molecule which contains a conservative set of genes in central part and genus- and species-specific genes near its ends, bounded by inverted terminal repeats. To the best of our knowledge, to date, TeAdV-1 has the shortest known ITR (25 bases) within the Adenoviridae family closest by length to the Siadenovirus representatives (Supplementary Table S2). TeAdV-1 closest relative, duck atadenovirus 1, has an ITR more than 2 times longer (53 nucleotides [60]. Unfortunately, to date, information on the functional significance of the length and sequence of the ITR region is limited and primarily concerns synthetic adenoviral vectors used to deliver target sequences.

The coding part of the TAdV genome contains all genes expected for AdVs as well as specific for the Atadenovirus genus. Genes are known to have splicing (IVa2, pTP, and $33 \mathrm{~K}$ ) were annotated manually using predicted splice sites. These results require confirmation by sequencing of mRNA transcripts produced in infected cells. Since the authors did not have the opportunity to obtain a viral culture, experimental confirmation of the results obtained remains the goal of future studies. We have also predicted 3D structures for a conserved set of structural proteins (penton base, hexon, fiber, LH2, and LH3) as well as for DNA-polymerase. For all TeAdV proteins, compared with corresponding proteins with known crystal structures belonging to other members of the Adenoviridae family, we observed a high level of structural similarity.

At the time this article was being prepared for publication, a partial genomic sequence of adenovirus isolated from tern (GenBank accession MW067004.1), obtained by another research group, was uploaded to the NSBI database with the annotated taxonomic position of the unclassified Adenoviridae (unpublished). Comparison of the sequences of the DNA polymerase and hexon genes of MW067004.1 showed high percentages of identity $(99.38 \%$ 
and $99.56 \%$ accordingly) with corresponding TeAdV-1 genes, indicating that MW067004.1 and the described TeAdV-1 virus belong to the same species. Thus, we propose to move MW067004.1 from unclassified Adenoviridae to the genus Atadenovirus.

All Atadenovirus species sequenced to date contain at least five genes derived from other organisms (their hosts, bacteria, fungi, or other viruses), or the origin of which is unknown [68-70]. These genes are diverse in their functions and are not required for the realization of the life cycle of the virus, however, apparently, they may contain evolutionary information about the history of the virus-hosts interactions. The genome of TeAdV-1 contains 8 hypothetical proteins, some of which have similarities with those of DAdV-1, and others-with the hypothetical proteins encoded in PsAdV-3 genomes [59]. This fact is fully consistent with the phylogenetic analysis carried out for the core genome, according to which TeAdV-1 descended from the most recent common ancestor (MRCA) of DAdV-1 and PsAdV-3. However, the genome of TeAdV-1 also contains a unique, hypothetical protein (ORF8) that was not found in the genomes of other organisms. The nucleotide sequence of ORF8 has also not been found in the genomes of organisms sequenced to date, including known sequences of the Sterna hirundo genome. Thus, the origin of this hypothetical protein remains unclear and requires further research.

Historically, the name of the Atadenovirus genus was chosen due to the high proportion of nucleotides $\mathrm{A}$ and $\mathrm{T}$ in the genomes of the representatives allocated to it [71]. However, only ruminant adenoviruses sequenced to date demonstrate a low proportion of $\mathrm{G}+\mathrm{C}$ nucleotides, on average about $34 \%$. Reptilian adenoviruses of this genus show a balanced nucleotide composition for Snake adenoviruses $A$ (on average about $50 \%$ ) and bearded dragon adenovirus 1 (56\%) [69] with the exception for lizard adenovirus 2, which has $44 \% \mathrm{G}+\mathrm{C}$ bases. For avian viruses of Atadenovirus known to date, similar statistics are observed: about $53 \% \mathrm{G}+\mathrm{C}$ nucleotides for passerine and psittacine adenoviruses, but biased for the DAdV-1 (43\%). Tern atadenovirus 1 genome has $34 \% \mathrm{G}+\mathrm{C}$ bases, which is the lowest rate among avian adenoviruses within the genus Atadenovirus and more consistent with ruminant ones. This fact, combined with phylogenetic information, does not support the assumption of a tendency towards a decrease in the proportion of $\mathrm{G}+\mathrm{C}$ bases in Atadenovirus genomes [69]. Variations in the composition of nucleotides can be a consequence of the adaptation of each viral species to the host organism. However, a recent study reported no correlation between the nucleotide composition of the pathogen and its host genome for eukaryotic viruses, in contrast to bacteriophages, for which such dependence was revealed [72], showing that changes in nucleotide composition for eukaryotic viruses may be caused by more complex adaptation processes.

In order to establish taxonomic relationships of TAdV-1, we also carried out a phylogenetic study. Most of the previously published phylogenies of the family Adenoviridae were obtained using the single-locus approach. To construct a phylogenetic tree, the alignment of the sequences of individual genes or proteins encoded by them, in particular, DNA-dependent DNA polymerase [1,73-75], hexon [4,76-78], penton base, or fiber-2 [59] is traditionally used.

Single gene-based trees, although generally congruent, often show inconsistency in topology and significant differences in the values of node supports. It is customary to explain this by the limited amount of evolutionary information that can be extracted from the single-locus alignment or by different rates of evolution of sequences at different loci [79-84]. Cases in which the use of the single-locus approach led to incorrect classification of AdVs have already been discovered. Thus, it has been shown that hexon gene sequencing can lead to a low-resolution view or even mischaracterization of a type of human AdVs (in particular, HAdV-D), since the gene readily undergoes recombination [85]. In the example of the genus Atadenovirus, it can be clearly seen that the limitations of the single-locus approach and the difference in the bioinformatic pipelines and tools used by different research groups lead to inconsistencies in the results of phylogenetic analysis. For instance, despite the high statistical support values in most of the cases considered below, the topology of nodes and branches within the Atadenovirus clade differs significantly in 
various published phylogenetic trees. The topologies obtained based on DNA polymerase sequence alignment published in studies [1] (bootstrap values > 90) and [75] (Bayesian Posterior Probability values $>0.7$ ) are not consistent with each other. The topologies obtained on the basis of hexon sequence alignment published in studies [76] (Bayesian Posterior Probability values $=1$ ), [4] (bootstrap values $>80$ ) and [78] (bootstrap values $>$ 80) are generally consistent but conflict with others topologies.

The idea that a larger number of characters improves phylogenetic accuracy and resolution, pioneered by Hillis in 1996 [86], contributed to the development of phylogenomics. The phylogenomic approach can be superior to single-gene analyses with respect to the resolution of internal branches as well as the position of taxa forming long branches in single-gene analyses [87]. Phylogenomic methods are much less limited by stochastic error or sampling error, which could potentially lead to poorly resolved or poorly supported phylogenetic trees, compared to single-loci methods [88]. Indeed, whole-genome sequence analysis has become the gold standard for the classification of adenoviruses as well [85].

Therefore, to build a phylogenetic tree we used the phylogenomic approach that is potentially able to confidently resolve the conflicts between the single-gene analyses of the Adenoviridae family, some of which were mentioned above. We used a reliable pipeline recommended for phylogenomic analysis [88], which includes essential stages of preparation and analysis of sequencing data. This allowed us to obtain a reliable phylogeny of the family Adenoviridae and the genus Atadenovirus, within which we localized the new virus TeAdV-1.

It is often difficult to determine if a strain belongs to a new species or is a variant of an existing species [89]. The previously mentioned divergence values of DNA polymerase, which is one of the most conserved proteins, were selected by the ICTV as the most important criterion for species delimitation [3]. According to this commonly used criterion, TAtV-1 does not belong to any previously described species of atadenoviruses, demonstrating values of the pairwise similarity of the amino acid sequence of DNA polymerase not exceeding 58.3\% (Figure 2). However, there are many other approaches to viral species delimitation. Several approaches and relevant tools that have been successfully used to analyze adenovirus genomes are reviewed in [90]. With the onset of the post-genomic era, the most widespread are phylogenetic analyses as well as tools based on the ANI (Average Nucleotide Identity) index [91], that is, an index of similarity between a given pair of genomes. Unfortunately, the ANI-like methods, similar to methods based on singlelocus distances, also have their drawbacks and are not ideal methods for classification or reclassification. The most important disadvantage is that there is no universal threshold, suitable for different organisms. Therefore, it needs to be set a priori in each analysis, which often seems to be difficult, and in some cases, even unsolvable problem. To establish an objective threshold, the existing classification must be complete and correct, which means that it should not contain any errors in the delimitation of taxonomic units.

In this study, to classify species, we used coalescent-based methods such as GMYC and PTP that combine population genetic and phylogenetic theory to provide an objective means for delimitation evolutionarily significant units of diversity. GMYC and PTP were originally designed for the analysis of single-locus data, but are often applied to concatenated multilocus data by postulating a shared genealogical history [92-94]. The methods generally perform well, being mostly congruent with each other and with the species partitions inferred from independent data [47], but have been shown to be sensitive to the reconstruction method [95]. This is another argument for the importance of using a reliable phylogenetic tree for the analysis. In addition to the above approaches, the ASAP method was used in this study. Compared to GMYC and PTP, ASAP utilizes a phenetic approach where similar sequences are clustered in the same group/species [47]. The difference in the approaches used to obtain species partitions allows more accurate verification of results obtained using different methods. Indeed, some authors propose that various methods should be applied jointly and the results compared [96]. The main advantage of the methods we use is that they propose de novo species partitions and do 
not require any a priori-defined intraspecific genetic distances. All the methods we used classified the virus TeAdV-1 as a separate novel species. Unfortunately, we were unable to apply the Birky index as an additional instrument for the classification of TeAdV-1, as this requires more than one genome belonging to the same species. This is the main limitation of this approach. However, we have successfully applied the rule to reclassify isolates KJ675568.1 and MN025529.1. Taking into account also the results of the species delimitation obtained using the programs GMYC and PTP, we suggest that the isolates KJ675568.1 and MN025529.1 need reclassification and should be attributed to individual species. The isolate MN025529.1 was first classified in a study [66]. Based on the results of phylogenetic analysis, the authors classified the virus as a new isolate belonging to the previously described species Psittacine atadenovirus $A$ [59]. The percentage of amino acid sequence identity was $90.2 \%$ for DNA polymerase and $97.2 \%$ for hexon. The authors, however, noted that, based on the criterion of the phylogenetic distance of DNA polymerase amino acid sequences, which suggests a species delimitation threshold of 10-15\% [97], some of the viruses identified may have had to be classified as a new species [66]. Our research has confirmed this assumption.

The robust classification of new species as well as the reclassification of previously described species according to reliable standards is an important issue. Therefore, we urge the authors not to rely solely on the criterion of the percent identity of the individual gene sequences as well as to use reliable tools and approaches for constructing phylogenetic trees.

It should be noted that according to the current criteria approved by the ICTV, species designation in the Atadenovirus genus depends on at least two of the following characteristics: phylogenetic distance $(>10-15 \%$, based on distance matrix analysis of the DNA polymerase amino acid sequence), host range, nucleotide composition, cross-neutralization and gene organization at the right end of the genome [ref]. As noted earlier, in addition to a solid pool of phylogenetic evidence, the TeAdV-1 virus does not share a host with any other described Atadenovirus species, has a different nucleotide composition from the most related species (e.g., GC-content), and also contains genes unique to its genome.

Pervasive selection, which we found in the core genes of all tested representatives of AdVs, confirms that the genus Atadenovirus (or even higher taxa) undergoes rapid gene evolution throughout the evolutionary history under consideration.

Genes and specific sites under pressure from the long-term positive selection can be significant in the arms race. Indeed, the phenomenon of pervasive selection is generally most prevalent in pathogen evolution and any biological system influenced by evolutionary arms race dynamics (or balancing selection), including adaptive immune escape by viruses [98]. This effect is also known as the Red Queen Hypothesis (RQH). The RQH suggests that the co-evolution of interacting species should drive molecular evolution through continual natural selection for adaptation and counter-adaptation [99,100]. The divergence observed at some host-resistance [101-103] and parasite-infectivity [104-107] genes is consistent with this. Development of the functional genetics of interactions and comparative analyses has also revealed that fast-evolving genes are commonly those at the interface of biotic interactions [108]. For instance, in a recent study of the ACE2 receptors, which are proteins that SARS-CoV and SARS-CoV-2, bind to invade the host cell, the gene was found under intense selection pressure in bats and positive selection in other selected mammalian hosts [109]. Binary antagonistic co-evolution is likely to be a major driver of evolutionary change within species.

We found sites under the pressure of pervasive positive selection in the genes encoding the following proteins of Atadenovirus representatives: DNA replication machinery (Pol, DBP, pTP) and capside proteins (III (penton base), pIIIa). Such sites are evolutionary hotspots under the constant pressure of adaptive selection and, summarizing all of the above, can be directly involved in antagonistic communication between the virus and host cells (Supplementary Tables S6 and S7). They also can be of epidemiological significance as they can hypothetically be used to predict potential antigenic determinants. It is known 
that epitope mutations are predominantly under positive selection because they affect the antigenic characteristics of a strain [104,105,110-114]. It should be noted that identifying specific sites is a rather difficult task. It is known that modern methods for site prediction often cannot reliably identify adaptive sites [115]. This may explain the inconsistency of the site detection results by two different methods: Bayesian (CODEML) and maximum likelihood (FEL). To understand adaptive evolution, some form of empirical confirmation is necessary. Nevertheless, the obtained data can be used as preliminary information for planning further experiments.

The episodic positive selection that we found in the TeAdV-1 genome confirms that the virus underwent rapid evolution. We found sites under the pressure of episodic positive selection $(P P \geq 0.7)$ in the genes, encoding the following proteins of the TAtV-1: DNA replication machinery (Pol, pTP), DNA packaging machinery (pIVa2), and $100 \mathrm{~K}$ protein. The specific sites we discovered are under the pressure of positive selection $(\omega>1)$ in the TeAdV-1 genome, while in the genomes of other representatives of Atadenovirus genus the sites mentioned above are under the pressure of negative selection $(\omega<1)$ or evolve neutrally $(\omega=1)$. Such independent events of adaptive evolution might be associated with the speciation process and adaptation to a new host. It has already been shown that positive selection can be associated with crossing the species barrier. As an example, episodic events of positive selection in the molecular evolution of bats rabies virus were detected during the repeated host shifts [107]. Our assumption that a host shift could be the driver of the TeAdV-1 rapid evolution looks plausible and is indirectly confirmed by the fact that among the most related species of Atadenovirus in the phylogenetic tree are species that infect birds (Psittacine atadenovirus $A$, Duck atadenovirus $A$ ). It is well known that host shifts tend to occur between related species [116].

Supplementary Materials: The following are available online at https:/ /www.mdpi.com/article/10 $.3390 /$ microorganisms10010031/s1, Table S1. List of predicted donor and acceptor splice sites in the TeAdV-1 genome. Data obtained using BDGP Splice Site Prediction by Neural Network [24]. The sites involved in the formation of protein sequences are marked with a $\left(^{*}\right)$ sign; Table S2. List of genomic sequences of AdVs used in the phylogenetic analysis; Table S3. List of genomic sequences of adenoviruses used in phylogenetic analysis of Atadenovirus genus; Table S4. List of reference sequences of Atadenovirus genus; Table S5. The length of the ITR region within the Adenoviridae family. Based on complete genome sequences, uploaded to the NCBI database (date of accession: 1 September 2021); Table S6. Homologous sequences of hypothetical proteins corresponding to the open reading frames of the variable region of the TAdV, founded by blast search; Table S7. Candidate sites for pervasive positive selection ( $P P \geq 0.7$ ), identified by CODEML; Table S8. Candidate sites for pervasive positive selection $(p \leq 0.1)$, identified by FEL; Table S9. Identified candidate sites for episodic positive selection. $P P$ values $\geq 0.95$ are in bold; Figure S1. Predicted 3D structures of proteins where candidate sites for positive selection were identified (marked with red color).

Author Contributions: Conceptualization, A.M. and M.D.; sample collection, I.A., V.B.; methodology, M.D., D.K. and A.S.; software, M.D. and I.M.; validation, A.M. and M.D.; formal analysis, A.M. and I.M.; writing-original draft preparation, A.M. and M.D.; writing-review and editing, K.K.; supervision, K.K. and G.S.; project administration, K.K. and G.S.; funding acquisition, K.K. and G.S. All authors have read and agreed to the published version of the manuscript.

Funding: Sample collection was funded by RSF, grant number 17-74-20096.

Institutional Review Board Statement: Ethical review and approval were waived for this study. The collection of samples was carried out without direct contact with animals, no invasive interventions with animals have been performed. According to the national laws, this study does not require ethical approval.

Informed Consent Statement: Not applicable.

Data Availability Statement: Tern atadenovirus 1 complete genome and annotation available in the GenBank database, accession number OL692338.

Conflicts of Interest: The authors declare no conflict of interest. 


\section{References}

1. Harrach, B.; Tarján, Z.L.; Benkő, M. Adenoviruses across the animal kingdom: A walk in the zoo. FEBS Lett. 2019, 593, 3660-3673. [CrossRef] [PubMed]

2. Lefkowitz, E.J.; Dempsey, D.M.; Hendrickson, R.C.; Orton, R.J.; Siddell, S.G.; Smith, D.B. Virus taxonomy: The database of the International Committee on Taxonomy of Viruses (ICTV). Nucleic Acids Res. 2018, 46, D708-D717. [CrossRef] [PubMed]

3. Benkő, M.; Aoki, K.; Arnberg, N.; Davison, A.J. ICTV Virus Taxonomy Profile: Adenoviridae. J. Gen. Virol. 2021, in press, ISBN 978-0-12-384684-6.

4. Davison, A.J.; Benko, M.; Harrach, B. Genetic content and evolution of adenoviruses. J. Gen. Virol. 2003, 84, 2895-2908. [CrossRef]

5. Gorman, J.J.; Wallis, T.P.; Whelan, D.A.; Shaw, J.; Both, G.W. LH3, a "homologue" of the mastadenoviral E1B 55-kDa protein is a structural protein of atadenoviruses. Virology 2005, 342, 159-166. [CrossRef]

6. Gerlach, H. Viruses. In Avian Medicine: Principles and Application; Ritchie, B.W., Harrison, G.J., Harrison, L.R., Eds.; Wingers Publishing Inc.: Lake Worth, FL, USA, 1994; pp. 862-948, ISBN 978-096369960.

7. Borkenhagen, L.K.; Fieldhouse, J.K.; Seto, D.; Gray, G.C. Are adenoviruses zoonotic? A systematic review of the evidence. Emerg. Microbes Infect. 2019, 8, 1679-1687. [CrossRef]

8. $\quad$ Li, K.S.; Guan, Y.; Wang, J.; Smith, G.J.D.; Xu, K.M.; Duan, L.; Rahardjo, A.P.; Puthavathana, P.; Buranathai, C.; Nguyen, T.D.; et al. Genesis of a highly pathogenic and potentially pandemic H5N1 influenza virus in eastern Asia. Nature 2004, 430, 209-213. [CrossRef]

9. World Health Organization Pandemic H1N1. 2009. Available online: http://apps.who.int/iris/bitstream/handle/10665/78414/ 9789241503051_eng.pdf?sequence=1 (accessed on 30 November 2021).

10. Neumann, G.; Noda, T.; Kawaoka, Y. Emergence and pandemic potential of swine-origin H1N1 influenza virus. Nature 2009, 459, 931-939. [CrossRef]

11. World Health Organization Statement on the second meeting of the International Health Regulations. 2020. Available online: https:/ / www.who.int/news/item/30-01-2020-statement-on-the-second-meeting-of-the-international-health-regulations(2005)-emergency-committee-regarding-the-outbreak-of-novel-coronavirus-(2019-ncov) (accessed on 30 November 2021).

12. Andersen, K.G.; Rambaut, A.; Lipkin, W.I.; Holmes, E.C.; Garry, R.F. The proximal origin of SARS-CoV-2. Nat. Med. 2020, 26, 450-452. [CrossRef]

13. Fritzsche McKay, A.; Hoye, B.J. Are Migratory Animals Superspreaders of Infection?: An Introduction to the Symposium. Integr. Comp. Biol. 2016, 56, 260-267. [CrossRef]

14. Ayginin, A.A.; Pimkina, E.V.; Matsvay, A.D.; Speranskaya, A.S.; Safonova, M.V.; Blinova, E.A.; Artyushin, I.V.; Dedkov, V.G.; Shipulin, G.A.; Khafizov, K. The Study of Viral RNA Diversity in Bird Samples Using De Novo Designed Multiplex Genus-Specific Primer Panels. Adv. Virol. 2018, 2018, 1-10. [CrossRef]

15. Bankevich, A.; Nurk, S.; Antipov, D.; Gurevich, A.A.; Dvorkin, M.; Kulikov, A.S.; Lesin, V.M.; Nikolenko, S.I.; Pham, S.; Prjibelski, A.D.; et al. SPAdes: A New Genome Assembly Algorithm and Its Applications to Single-Cell Sequencing. J. Comput. Biol. 2012, 19, 455-477. [CrossRef]

16. McGinnis, S.; Madden, T.L. BLAST: At the core of a powerful and diverse set of sequence analysis tools. Nucleic Acids Res. 2004, 32, W20-W25. [CrossRef]

17. Federhen, S. The NCBI Taxonomy database. Nucleic Acids Res. 2012, 40, D136-D143. [CrossRef]

18. Li, H.; Durbin, R. Fast and accurate short read alignment with Burrows-Wheeler transform. Bioinforma. Oxf. Engl. 2009, 25, 1754-1760. [CrossRef]

19. Li, H.; Handsaker, B.; Wysoker, A.; Fennell, T.; Ruan, J.; Homer, N.; Marth, G.; Abecasis, G.; Durbin, R.; 1000 Genome Project Data Processing Subgroup. The Sequence Alignment/Map format and SAMtools. Bioinforma. Oxf. Engl. 2009, 25, $2078-2079$. [CrossRef]

20. Milne, I.; Stephen, G.; Bayer, M.; Cock, P.J.A.; Pritchard, L.; Cardle, L.; Shaw, P.D.; Marshall, D. Using Tablet for visual exploration of second-generation sequencing data. Brief. Bioinform. 2013, 14, 193-202. [CrossRef]

21. Kurtz, S.; Phillippy, A.; Delcher, A.L.; Smoot, M.; Shumway, M.; Antonescu, C.; Salzberg, S.L. Versatile and open software for comparing large genomes. Genome Biol. 2004, 5, R12. [CrossRef]

22. Zhang, K.-Y.; Gao, Y.-Z.; Du, M.-Z.; Liu, S.; Dong, C.; Guo, F.-B. Vgas: A Viral Genome Annotation System. Front. Microbiol. 2019, 10, 184. [CrossRef]

23. Emms, D.M.; Kelly, S. OrthoFinder: Phylogenetic orthology inference for comparative genomics. Genome Biol. 2019, 20, 238. [CrossRef]

24. Reese, M.G.; Eeckman, F.H.; Kulp, D.; Haussler, D. Improved Splice Site Detection in Genie. J. Comput. Biol. 1997, 4, 311-323. [CrossRef]

25. Cock, P.J.A.; Antao, T.; Chang, J.T.; Chapman, B.A.; Cox, C.J.; Dalke, A.; Friedberg, I.; Hamelryck, T.; Kauff, F.; Wilczynski, B.; et al. Biopython: Freely available Python tools for computational molecular biology and bioinformatics. Bioinforma. Oxf. Engl. 2009, 25, 1422-1423. [CrossRef]

26. Clark, K.; Karsch-Mizrachi, I.; Lipman, D.J.; Ostell, J.; Sayers, E.W. GenBank. Nucleic Acids Res. 2016, 44, D67-D72. [CrossRef] 
27. Larkin, M.A.; Blackshields, G.; Brown, N.P.; Chenna, R.; McGettigan, P.A.; McWilliam, H.; Valentin, F.; Wallace, I.M.; Wilm, A.; Lopez, R.; et al. Clustal W and Clustal X version 2.0. Bioinforma. Oxf. Engl. 2007, 23, 2947-2948. [CrossRef]

28. Kumar, S.; Stecher, G.; Li, M.; Knyaz, C.; Tamura, K. MEGA X: Molecular Evolutionary Genetics Analysis across Computing Platforms. Mol. Biol. Evol. 2018, 35, 1547-1549. [CrossRef]

29. Castresana, J. Selection of Conserved Blocks from Multiple Alignments for Their Use in Phylogenetic Analysis. Mol. Biol. Evol. 2000, 17, 540-552. [CrossRef]

30. Lanfear, R.; Frandsen, P.B.; Wright, A.M.; Senfeld, T.; Calcott, B. PartitionFinder 2: New Methods for Selecting Partitioned Models of Evolution for Molecular and Morphological Phylogenetic Analyses. Mol. Biol. Evol. 2017, 34, 772-773. [CrossRef]

31. Kozlov, A.M.; Darriba, D.; Flouri, T.; Morel, B.; Stamatakis, A. RAxML-NG: A fast, scalable and user-friendly tool for maximum likelihood phylogenetic inference. Bioinformatics 2019, 35, 4453-4455. [CrossRef]

32. Rambaut, A. FigTree v. 1.4.3. 2018. Available online: http://tree.bio.ed.ac.uk/software/figtree/ (accessed on 30 November 2021)

33. Abadi, S.; Azouri, D.; Pupko, T.; Mayrose, I. Model selection may not be a mandatory step for phylogeny reconstruction. Nat. Commun. 2019, 10, 934. [CrossRef]

34. Spielman, S.J. Relative Model Fit Does Not Predict Topological Accuracy in Single-Gene Protein Phylogenetics. Mol. Biol. Evol. 2020, 37, 2110-2123. [CrossRef]

35. Letunic, I.; Bork, P. Interactive Tree Of Life (iTOL) v5: An online tool for phylogenetic tree display and annotation. Nucleic Acids Res. 2021, 49, W293-W296. [CrossRef] [PubMed]

36. Katoh, K. MAFFT: A novel method for rapid multiple sequence alignment based on fast Fourier transform. Nucleic Acids Res. 2002, 30, 3059-3066. [CrossRef] [PubMed]

37. Zhang, J.; Kapli, P.; Pavlidis, P.; Stamatakis, A. A general species delimitation method with applications to phylogenetic placements. Bioinformatics 2013, 29, 2869-2876. [CrossRef] [PubMed]

38. Fujisawa, T.; Barraclough, T.G. Delimiting Species Using Single-Locus Data and the Generalized Mixed Yule Coalescent Approach: A Revised Method and Evaluation on Simulated Data Sets. Syst. Biol. 2013, 62, 707-724. [CrossRef]

39. Pons, J.; Barraclough, T.G.; Gomez-Zurita, J.; Cardoso, A.; Duran, D.P.; Hazell, S.; Kamoun, S.; Sumlin, W.D.; Vogler, A.P. Sequence-Based Species Delimitation for the DNA Taxonomy of Undescribed Insects. Syst. Biol. 2006, 55, 595-609. [CrossRef]

40. Fontaneto, D.; Herniou, E.A.; Boschetti, C.; Caprioli, M.; Melone, G.; Ricci, C.; Barraclough, T.G. Independently Evolving Species in Asexual Bdelloid Rotifers. PLoS Biol. 2007, 5, e87. [CrossRef]

41. Birky, C.W., Jr.; Ricci, C.; Melone, G.; Fontaneto, D. Integrating DNA and morphological taxonomy to describe diversity in poorly studied microscopic animals: New species of the genus Abrochtha Bryce, 1910 (Rotifera: Bdelloidea: Philodinavidae): NEW CRYPTIC ROTIFER SPECIES. Zool. J. Linn. Soc. 2011, 161, 723-734. [CrossRef]

42. Yule, G.U. II.-A mathematical theory of evolution, based on the conclusions of Dr. J. C. Willis, F.R.S. Philos. Trans. R. Soc. Lond. Ser. B Contain. Pap. Biol. Character 1925, 213, 21-87. [CrossRef]

43. Hudson, R. Gene genealogies and the coalescent process. Oxf. Surv. Evol. Biol. 1990, 7, 1-44.

44. Tamura, K.; Battistuzzi, F.U.; Billing-Ross, P.; Murillo, O.; Filipski, A.; Kumar, S. Estimating divergence times in large molecular phylogenies. Proc. Natl. Acad. Sci. USA 2012, 109, 19333-19338. [CrossRef]

45. Tamura, K.; Tao, Q.; Kumar, S. Theoretical Foundation of the RelTime Method for Estimating Divergence Times from Variable Evolutionary Rates. Mol. Biol. Evol. 2018, 35, 1770-1782. [CrossRef]

46. Thomas, R.H. Molecular Evolution and Phylogenetics. Heredity 2001, 86, 385. [CrossRef]

47. Puillandre, N.; Brouillet, S.; Achaz, G. ASAP: Assemble species by automatic partitioning. Mol. Ecol. Resour. 2021, 21, 609-620. [CrossRef]

48. Boc, A.; Diallo, A.B.; Makarenkov, V. T-REX: A web server for inferring, validating and visualizing phylogenetic trees and networks. Nucleic Acids Res. 2012, 40, W573-W579. [CrossRef]

49. Birky, C.W.; Adams, J.; Gemmel, M.; Perry, J. Using Population Genetic Theory and DNA Sequences for Species Detection and Identification in Asexual Organisms. PLoS ONE 2010, 5, e10609. [CrossRef]

50. Kosakovsky Pond, S.L.; Posada, D.; Gravenor, M.B.; Woelk, C.H.; Frost, S.D.W. GARD: A genetic algorithm for recombination detection. Bioinformatics 2006, 22, 3096-3098. [CrossRef]

51. Pond, S.L.K.; Muse, S.V. HyPhy: Hypothesis Testing Using Phylogenies. In Statistical Methods in Molecular Evolution; Springer: New York, NY, USA, 2005; pp. 125-181. ISBN 978-0-387-22333-9.

52. Yang, Z. PAML 4: Phylogenetic Analysis by Maximum Likelihood. Mol. Biol. Evol. 2007, 24, 1586-1591. [CrossRef]

53. Kosakovsky Pond, S.L.; Frost, S.D.W. Not So Different After All: A Comparison of Methods for Detecting Amino Acid Sites Under Selection. Mol. Biol. Evol. 2005, 22, 1208-1222. [CrossRef]

54. Zhang, J. Evaluation of an Improved Branch-Site Likelihood Method for Detecting Positive Selection at the Molecular Level. Mol. Biol. Evol. 2005, 22, 2472-2479. [CrossRef]

55. Jumper, J.; Evans, R.; Pritzel, A.; Green, T.; Figurnov, M.; Ronneberger, O.; Tunyasuvunakool, K.; Bates, R.; Žídek, A.; Potapenko, A.; et al. Highly accurate protein structure prediction with AlphaFold. Nature 2021, 596, 583-589. [CrossRef]

56. Pettersen, E.F.; Goddard, T.D.; Huang, C.C.; Couch, G.S.; Greenblatt, D.M.; Meng, E.C.; Ferrin, T.E. UCSF Chimera?A visualization system for exploratory research and analysis. J. Comput. Chem. 2004, 25, 1605-1612. [CrossRef] 
57. Marabini, R.; Condezo, G.N.; Krupovic, M.; Menéndez-Conejero, R.; Gómez-Blanco, J.; San Martín, C. Near-atomic structure of an atadenovirus reveals a conserved capsid-binding motif and intergenera variations in cementing proteins. Sci. Adv. 2021, 7, eabe6008. [CrossRef]

58. Kundhavai Natchiar, S.; Venkataraman, S.; Mullen, T.-M.; Nemerow, G.R.; Reddy, V.S. Revised Crystal Structure of Human Adenovirus Reveals the Limits on Protein IX Quasi-Equivalence and on Analyzing Large Macromolecular Complexes. J. Mol. Biol. 2018, 430, 4132-4141. [CrossRef]

59. To, K.K.W.; Tse, H.; Chan, W.-M.; Choi, G.K.Y.; Zhang, A.J.X.; Sridhar, S.; Wong, S.C.Y.; Chan, J.F.W.; Chan, A.S.F.; Woo, P.C.Y.; et al. A Novel Psittacine Adenovirus Identified During an Outbreak of Avian Chlamydiosis and Human Psittacosis: Zoonosis Associated with Virus-Bacterium Coinfection in Birds. PLoS Negl. Trop. Dis. 2014, 8, e3318. [CrossRef]

60. Harrach, B. Adenoviruses: General Features. In Reference Module in Biomedical Sciences; Elsevier: Amsterdam, The Netherlands, 2014; p. B978012801238302523X, ISBN 978-0-12-801238-3.

61. Cepko, C.L.; Sharp, P.A. Analysis of Ad5 Hexon and 100K is mutants using conformation-specific monoclonal antibodies. Virology 1983, 129, 137-154. [CrossRef]

62. Russell, W.C. Adenoviruses: Update on structure and function. J. Gen. Virol. 2009, 90, 1-20. [CrossRef]

63. Kulanayake, S.; Tikoo, S.K. Adenovirus Core Proteins: Structure and Function. Viruses 2021, 13, 388. [CrossRef]

64. Parker, E. Adenovirus DNA polymerase: Domain organisation and interaction with preterminal protein. Nucleic Acids Res. 1998, 26, 1240-1247. [CrossRef]

65. Vellinga, J.; Van der Heijdt, S.; Hoeben, R.C. The adenovirus capsid: Major progress in minor proteins. J. Gen. Virol. 2005, 86, 1581-1588. [CrossRef]

66. Duarte, M.A.; Silva, J.M.F.; Brito, C.R.; Teixeira, D.S.; Melo, F.L.; Ribeiro, B.M.; Nagata, T.; Campos, F.S. Faecal Virome Analysis of Wild Animals from Brazil. Viruses 2019, 11, 803. [CrossRef]

67. Shriner, D.; Nickle, D.C.; Jensen, M.A.; Mullins, J.I. Potential impact of recombination on sitewise approaches for detecting positive natural selection. Genet. Res. 2003, 81, 115-121. [CrossRef] [PubMed]

68. Vrati, S.; Brookes, D.E.; Strike, P.; Khatri, A.; Boyle, D.B.; Both, G.W. Unique Genome Arrangement of an Ovine Adenovirus: Identification of New Proteins and Proteinase Cleavage Sites. Virology 1996, 220, 186-199. [CrossRef] [PubMed]

69. Pénzes, J.J.; Szirovicza, L.; Harrach, B. The complete genome sequence of bearded dragon adenovirus 1 harbors three genes encoding proteins of the C-type lectin-like domain superfamily. Infect. Genet. Evol. 2020, 83, 104321. [CrossRef] [PubMed]

70. Athukorala, A.; Forwood, J.K.; Phalen, D.N.; Sarker, S. Molecular Characterisation of a Novel and Highly Divergent Passerine Adenovirus 1. Viruses 2020, 12, 1036. [CrossRef]

71. Benkö, M.; Harrach, B. A proposal for a new (third) genus within the family Adenoviridae. Arch. Virol. 1998, $143,829-837$. [CrossRef]

72. Simón, D.; Cristina, J.; Musto, H. Nucleotide Composition and Codon Usage Across Viruses and Their Respective Hosts. Front Microbiol. 2021, 12, 646300. [CrossRef]

73. Maeda, K.; Hondo, E.; Terakawa, J.; Kiso, Y.; Nakaichi, N.; Endoh, D.; Sakai, K.; Morikawa, S.; Mizutani, T. Isolation of Novel Adenovirus from Fruit Bat (Pteropus dasymallus yayeyamae). Emerg. Infect. Dis. 2008, 14, 347-349. [CrossRef]

74. Prado-Irwin, S.R.; van de Schoot, M.; Geneva, A.J. Detection and phylogenetic analysis of adenoviruses occurring in a single anole species. PeerJ 2018, 6, e5521. [CrossRef]

75. Wellehan, J.F.X.; Greenacre, C.B.; Fleming, G.J.; Stetter, M.D.; Childress, A.L.; Terrell, S.P. Siadenovirus infection in two psittacine bird species. Avian Pathol. 2009, 38, 413-417. [CrossRef]

76. Conrardy, C.; Tao, Y.; Kuzmin, I.V.; Niezgoda, M.; Agwanda, B.; Breiman, R.F.; Anderson, L.J.; Rupprecht, C.E.; Tong, S. Molecular Detection of Adenoviruses, Rhabdoviruses, and Paramyxoviruses in Bats from Kenya. Am. J. Trop. Med. Hyg. 2014, 91, 258-266. [CrossRef]

77. Geisbert, T.W.; Bailey, M.; Hensley, L.; Asiedu, C.; Geisbert, J.; Stanley, D.; Honko, A.; Johnson, J.; Mulangu, S.; Pau, M.G.; et al. Recombinant Adenovirus Serotype 26 (Ad26) and Ad35 Vaccine Vectors Bypass Immunity to Ad5 and Protect Nonhuman Primates against Ebolavirus Challenge. J. Virol. 2011, 85, 4222-4233. [CrossRef]

78. Adenoviridae. In Virus Taxonomy; Elsevier: Amsterdam, The Netherlands, 2012; pp. 125-141, ISBN 978-0-12-384684-6.

79. Capesius, I.; Bopp, M. New classification of liverworts based on molecular and morphological data. Plant Syst. Evol. 1997, 207, 87-97. [CrossRef]

80. Nei, M.; Kumar, S.; Takahashi, K. The optimization principle in phylogenetic analysis tends to give incorrect topologies when the number of nucleotides or amino acids used is small. Proc. Natl. Acad. Sci. USA 1998, 95, 12390-12397. [CrossRef]

81. Poe, S.; Swofford, D.L. Taxon sampling revisited. Nature 1999, 398, 299-300. [CrossRef]

82. Nickrent, D.L.; Parkinson, C.L.; Palmer, J.D.; Duff, R.J. Multigene Phylogeny of Land Plants with Special Reference to Bryophytes and the Earliest Land Plants. Mol. Biol. Evol. 2000, 17, 1885-1895. [CrossRef]

83. Hervé, P. Opinion: Long Branch Attraction and Protist Phylogeny. Protist 2000, 151, 307-316. [CrossRef]

84. Hoef-Emden, K.; Marin, B.; Melkonian, M. Nuclear and Nucleomorph SSU rDNA Phylogeny in the Cryptophyta and the Evolution of Cryptophyte Diversity. J. Mol. Evol. 2002, 55, 161-179. [CrossRef]

85. Singh, G.; Robinson, C.M.; Dehghan, S.; Schmidt, T.; Seto, D.; Jones, M.S.; Dyer, D.W.; Chodosh, J. Overreliance on the Hexon Gene, Leading to Misclassification of Human Adenoviruses: Fig 1. J. Virol. 2012, 86, 4693-4695. [CrossRef] 
86. Hillis, D.M. Inferring complex phytogenies. Nature 1996, 383, 130-131. [CrossRef]

87. Gontcharov, A.A. Are Combined Analyses Better Than Single Gene Phylogenies? A Case Study Using SSU rDNA and rbcL Sequence Comparisons in the Zygnematophyceae (Streptophyta). Mol. Biol. Evol. 2003, 21, 612-624. [CrossRef]

88. Young, A.D.; Gillung, J.P. Phylogenomics-Principles, opportunities and pitfalls of big-data phylogenetics. Syst. Entomol. 2020, 45, 225-247. [CrossRef]

89. Teng, J.L.L.; Tang, Y.; Huang, Y.; Guo, F.-B.; Wei, W.; Chen, J.H.K.; Wong, S.S.Y.; Lau, S.K.P.; Woo, P.C.Y. Phylogenomic Analyses and Reclassification of Species within the Genus Tsukamurella: Insights to Species Definition in the Post-genomic Era. Front. Microbiol. 2016, 7, 1137. [CrossRef]

90. Mahadevan, P. An Analysis of Adenovirus Genomes Using Whole Genome Software Tools. Bioinformation 2016, 12, 301-310. [CrossRef]

91. Konstantinidis, K.T.; Tiedje, J.M. Genomic insights that advance the species definition for prokaryotes. Proc. Natl. Acad. Sci. USA 2005, 102, 2567-2572. [CrossRef]

92. Arrigoni, R.; Berumen, M.L.; Chen, C.A.; Terraneo, T.I.; Baird, A.H.; Payri, C.; Benzoni, F. Species delimitation in the reef coral genera Echinophyllia and Oxypora (Scleractinia, Lobophylliidae) with a description of two new species. Mol. Phylogenet. Evol. 2016, 105, 146-159. [CrossRef]

93. Renner, M.A.M.; Heslewood, M.M.; Patzak, S.D.F.; Schäfer-Verwimp, A.; Heinrichs, J. By how much do we underestimate species diversity of liverworts using morphological evidence? An example from Australasian Plagiochila (Plagiochilaceae: Jungermanniopsida). Mol. Phylogenet. Evol. 2017, 107, 576-593. [CrossRef] [PubMed]

94. Nieto-Montes de Oca, A.; Barley, A.J.; Meza-Lázaro, R.N.; García-Vázquez, U.O.; Zamora-Abrego, J.G.; Thomson, R.C.; Leaché, A.D. Phylogenomics and species delimitation in the knob-scaled lizards of the genus Xenosaurus (Squamata: Xenosauridae) using ddRADseq data reveal a substantial underestimation of diversity. Mol. Phylogenet. Evol. 2017, 106, 241-253. [CrossRef] [PubMed]

95. Tang, C.Q.; Humphreys, A.M.; Fontaneto, D.; Barraclough, T.G. Effects of phylogenetic reconstruction method on the robustness of species delimitation using single-locus data. Methods Ecol. Evol. 2014, 5, 1086-1094. [CrossRef] [PubMed]

96. Ducasse, J.; Ung, V.; Lecointre, G.; Miralles, A. LIMES: A tool for comparing species partition. Bioinformatics 2020, 36, 2282-2283. [CrossRef] [PubMed]

97. International Committee on Taxonomy of Viruses Virus Taxonomy: The ICTV Report on Virus Classification and Taxon Nomenclature. Available online: https://talk.ictvonline.org/ictv-reports/ictv_online_report/ (accessed on 30 November 2021).

98. Spielman, S.J.; Weaver, S.; Shank, S.D.; Magalis, B.R.; Li, M.; Kosakovsky Pond, S.L. Evolution of Viral Genomes: Interplay Between Selection, Recombination, and Other Forces. In Evolutionary Genomics; Anisimova, M., Ed.; Springer: New York, NY, USA, 2019; Volume 1910, pp. 427-468, ISBN 978-1-4939-9073-3.

99. Van Valen, L. Molecular evolution as predicted by natural selection. J. Mol. Evol. 1974, 3, 89-101. [CrossRef]

100. Stenseth, N.; Smith, J.M. Coevolution in Ecosystems: Red Queen Evolution or Stasis? Evolution 1984, 38, 870. [CrossRef]

101. Hedrick, P.W. Evolutionary Genetics of the Major Histocompatibility Complex. Am. Nat. 1994, 143, 945-964. [CrossRef]

102. Obbard, D.J.; Jiggins, F.M.; Halligan, D.L.; Little, T.J. Natural Selection Drives Extremely Rapid Evolution in Antiviral RNAi Genes. Curr. Biol. 2006, 16, 580-585. [CrossRef]

103. Drosophila 12 Genomes Consortium Evolution of genes and genomes on the Drosophila phylogeny. Nature 2007, 450, 203-218. [CrossRef]

104. Blanc, G.; Ngwamidiba, M.; Ogata, H.; Fournier, P.-E.; Claverie, J.-M.; Raoult, D. Molecular Evolution of Rickettsia Surface Antigens: Evidence of Positive Selection. Mol. Biol. Evol. 2005, 22, 2073-2083. [CrossRef]

105. Mu, J.; Awadalla, P.; Duan, J.; McGee, K.M.; Keebler, J.; Seydel, K.; McVean, G.A.T.; Su, X. Genome-wide variation and identification of vaccine targets in the Plasmodium falciparum genome. Nat. Genet. 2007, 39, 126-130. [CrossRef]

106. Barrett, L.G.; Thrall, P.H.; Dodds, P.N.; van der Merwe, M.; Linde, C.C.; Lawrence, G.J.; Burdon, J.J. Diversity and Evolution of Effector Loci in Natural Populations of the Plant Pathogen Melampsora lini. Mol. Biol. Evol. 2009, 26, 2499-2513. [CrossRef]

107. Streicker, D.G.; Altizer, S.M.; Velasco-Villa, A.; Rupprecht, C.E. Variable evolutionary routes to host establishment across repeated rabies virus host shifts among bats. Proc. Natl. Acad. Sci. USA 2012, 109, 19715-19720. [CrossRef]

108. Brockhurst, M.A.; Chapman, T.; King, K.C.; Mank, J.E.; Paterson, S.; Hurst, G.D.D. Running with the Red Queen: The role of biotic conflicts in evolution. Proc. R. Soc. B Biol. Sci. 2014, 281, 20141382. [CrossRef]

109. Frank, H.K.; Enard, D.; Boyd, S.D. Exceptional diversity and selection pressure on SARS-CoV and SARS-CoV-2 host receptor in bats compared to other mammals. bioRxiv 2020. [CrossRef]

110. Shih, A.C.-C.; Hsiao, T.-C.; Ho, M.-S.; Li, W.-H. Simultaneous amino acid substitutions at antigenic sites drive influenza A hemagglutinin evolution. Proc. Natl. Acad. Sci. USA 2007, 104, 6283-6288. [CrossRef]

111. Bhatt, S.; Holmes, E.C.; Pybus, O.G. The Genomic Rate of Molecular Adaptation of the Human Influenza A Virus. Mol. Biol. Evol. 2011, 28, 2443-2451. [CrossRef]

112. Strelkowa, N.; Lässig, M. Clonal Interference in the Evolution of Influenza. Genetics 2012, 192, 671-682. [CrossRef]

113. Illingworth, C.J.R.; Mustonen, V. Components of Selection in the Evolution of the Influenza Virus: Linkage Effects Beat Inherent Selection. PLoS Pathog. 2012, 8, e1003091. [CrossRef] 
114. Meyer, A.G.; Dawson, E.T.; Wilke, C.O. Cross-species comparison of site-specific evolutionary-rate variation in influenza haemagglutinin. Philos. Trans. R. Soc. B Biol. Sci. 2013, 368, 20120334. [CrossRef]

115. Nozawa, M.; Suzuki, Y.; Nei, M. Reliabilities of identifying positive selection by the branch-site and the site-prediction methods. Proc. Natl. Acad. Sci. USA 2009, 106, 6700-6705. [CrossRef]

116. Longdon, B.; Day, J.P.; Alves, J.M.; Smith, S.C.L.; Houslay, T.M.; McGonigle, J.E.; Tagliaferri, L.; Jiggins, F.M. Host shifts result in parallel genetic changes when viruses evolve in closely related species. PLoS Pathog. 2018, 14, e1006951. [CrossRef] 